\title{
Mutually consistent thermodynamic potentials for fluid water, ice and seawater: a new standard for oceanography
}

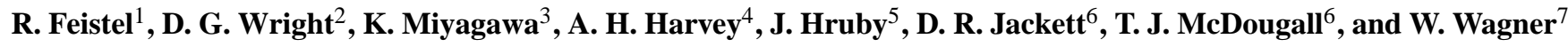 \\ ${ }^{1}$ Leibniz Institute for Baltic Sea Research, 18119 Warnemünde, Germany \\ ${ }^{2}$ Bedford Institute of Oceanography, Dartmouth, NS, Canada \\ ${ }^{3}$ 4-12-11-628, Nishiogu, Arakawa-ku, Tokyo 116-0011, Japan \\ ${ }^{4}$ National Institute of Standards and Technology, Boulder, CO 80305, USA \\ ${ }^{5}$ Institute of Thermomechanics of the ASCR, v.v.i., Prague, Czech Republic \\ ${ }^{6}$ Centre for Australian Weather and Climate Research: A partnership between CSIRO and the Bureau of Meteorology, \\ Hobart, TAS, Australia \\ ${ }^{7}$ Ruhr-Universität Bochum, 44780 Bochum, Germany
}

Received: 5 June 2008 - Published in Ocean Sci. Discuss.: 11 July 2008

Revised: 29 October 2008 - Accepted: 18 November 2008 - Published: 12 December 2008

\begin{abstract}
A new seawater standard for oceanographic and engineering applications has been developed that consists of three independent thermodynamic potential functions, derived from extensive distinct sets of very accurate experimental data. The results have been formulated as Releases of the International Association for the Properties of Water and Steam, IAPWS $(1996,2006,2008)$ and are expected to be adopted internationally by other organizations in subsequent years. In order to successfully perform computations such as phase equilibria from combinations of these potential functions, mutual compatibility and consistency of these independent mathematical functions must be ensured. In this article, a brief review of their separate development and ranges of validity is given. We analyse background details on the conditions specified at their reference states, the triple point and the standard ocean state, to ensure the mutual consistency of the different formulations, and the necessity and possibility of numerically evaluating metastable states of liquid water. Computed from this formulation in quadruple precision (128-bit floating point numbers), tables of numerical reference values are provided as anchor points for the consistent incorporation of additional potential functions in the future, and as unambiguous benchmarks to be used in the determination of numerical uncertainty estimates of doubleprecision implementations on different platforms that may be customized for special purposes.
\end{abstract}

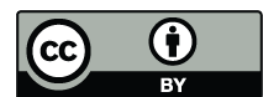

Correspondence to: R. Feistel (rainer.feistel@io-warnemuende.de)

\section{Introduction}

The International Equation of State of Seawater (EOS-80, Fofonoff and Millard 1983) has successfully served the needs of oceanographers for three decades. Challenged by climate change, equipped with more powerful computers, and confronted with new and more accurate standards in related fields of science and technology, the SCOR/IAPSO Working Group 127 (WG127) was established and charged with developing a new seawater standard for oceanography.

The very accurate mathematical description of liquid water and vapor, IAPWS-95, issued by the International Association for the Properties of Water and Steam in the form of a Helmholtz potential (Wagner and Pruß, 2002) has provided the foundation for the cooperative development of a common seawater formulation for both oceanographic and engineering applications worldwide. To complement the Helmholtz potential for pure water, an equation of state for salt-free ice was developed in the form of a Gibbs potential function (Feistel and Wagner, 2006), presented at the 14th International Conference on the Properties of Water and Steam (ICPWS) in Kyoto in 2004, and approved by IAPWS as a Release in 2006. Together, the Helmholtz and the Gibbs potentials cover all three stable phases of pure water found under terrestrial conditions in a consistent, comprehensive and precise way. To use the IAPWS-95 formulation over the required application range for seawater, the implementations of IAPWS-95 must be able to provide results for metastable states of liquid water; i.e., conditions of temperature and pressure under which seawater is a stable liquid, but pure

Published by Copernicus Publications on behalf of the European Geosciences Union. 


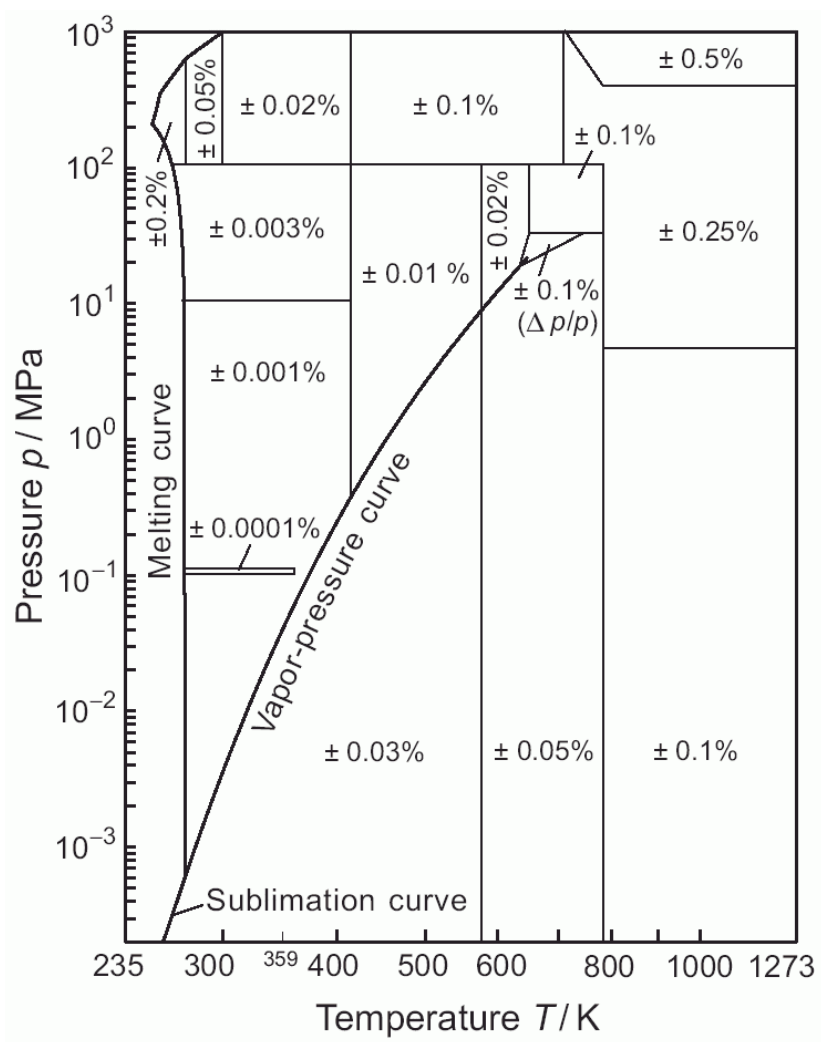

Fig. 1. Range of validity (excluding the ice phases at the left border line) and uncertainty of water density in the IAPWS-95 formulation.

water is already transformed into ice or vapor. A discussion of this work is presented in Sect. 4.

The presence of sea salt in water changes water's thermodynamic properties. The saline part of a Gibbs potential of seawater (i.e., the addition to the Gibbs potential of pure water required to represent seawater) has now been determined for the quantitative description of these deviations (Feistel, 2003, 2008). For its application to seawater under extreme natural conditions or in technical systems such as desalination plants, the range of validity of the saline Gibbs function has been extended to $80^{\circ} \mathrm{C}$ and covers salinities extending from 0 to $120 \mathrm{~g} / \mathrm{kg}$, for which experimental data of adequate accuracy are available. The salinity range extends beyond the currently valid Practical Salinity Scale of 1978, PSS-78, at both low and high values. This problem is circumvented by using a new salinity scale termed Reference-Composition Salinity that was developed by WG127 (Millero et al., 2008). Saturation conditions for particular components of sea salt are discussed by Marion et al. (2008a, b).

The combination of the Helmholtz function for pure water, the Gibbs potential for salt-free ice and the saline part of the Gibbs potential provide the foundation for the computation of the thermodynamic properties of pure water and sea water within a new, unified and fully consistent framework.
Our approach of constructing a new seawater standard explicitly from three distinct thermodynamic potential functions is unprecedented and has not been discussed in the scientific literature before. We discuss the conditions that need to be met to realize this novel approach as well as the solutions found to overcome the problems encountered. The ambiguities of different triple-point definitions and their implications for the formulation of seawater thermodynamics are analysed in Sect. 3. Revising earlier definitions (Feistel, 1993, 2003; Feistel and Hagen, 1995), the new WG127 specification of the seawater reference point is given and its properties are considered in detail in the same section.

In the appendix, highly accurate numerical values for the properties at the reference states of water and seawater are provided. In particular, we have recomputed the numerical check values published in the Releases IAPWS-95 for fluid water, IAPWS-06 for ice and IAPWS-08 for seawater (IAPWS, 2008), using quadruple-precision calculations, and these are presented to 20 significant figures. These results provide unambiguous benchmarks against which doubleprecision implementations of the new seawater standard on different platforms can be validated.

In this paper, formula symbols are used which in some cases deviate from the common symbols used in oceanography. In particular, $p$ is absolute pressure (in $\mathrm{Pa}, \mathrm{MPa}$, etc.) rather than sea pressure (relative to $p_{0}=101325 \mathrm{~Pa}$ ), and $w$ is sound speed (in $\mathrm{m} / \mathrm{s}$ ). $S_{\mathrm{A}}$ is used to represent Absolute Salinity, which we note is not accurately represented by Practical Salinity. For the relation between Absolute and Practical Salinity, see Millero et al. (2008).

\section{Development of the formulations}

In 1984, the International Association for the Properties of Steam (IAPS) adopted the Helmholtz potential developed by Haar et al. $(1982,1984)$ as the international standard sometimes referred to as IAPS-84. At its 1990 meeting in Buenos Aires, IAPWS (the successor of IAPS) agreed on the need for a replacement of IAPS-84 which should be based on the ITS-90 temperature scale, represent a wider range of data, and better represent the critical and the metastable regions. This led to the approval of the Helmholtz function developed by Pruß and Wagner (1995) as the formulation IAPWS-95, which was adopted in its final form by IAPWS (1996) in Fredericia, Denmark, and is described in detail by Wagner and Pruß (2002). Its validity range in temperature and pressure is shown in Fig. 1. Fortran source code of an implementation is available from the digital supplement of Feistel et al. (2008).

The first Gibbs functions for ice Ih were proposed by Feistel and Hagen (1995, 1998), Tillner-Roth (1998) and Feistel (2003). These functions were derived from only a few experimental data sets, restricted in validity to the vicinity of the melting curve, and possessed significant uncertainties, in 
particular in compressibility. In a subsequent, more comprehensive approach, the entire region of existence of ice Ih was covered by a new Gibbs function developed by Feistel and Wagner (2005). Its source code was published by Feistel et al. (2005) in the digital supplement. An improved version including additional data, in particular for the absolute entropy at the melting point (Feistel and Wagner, 2006), was adopted by IAPWS (2006) in Witney, UK. The range of validity of this formulation, which we will refer to as IAPWS-06, is shown in Fig. 2. Its source code with the updated coefficients is available from Feistel et al. (2008).

Ice Ih is the ice phase I that occurs under normal pressure and temperature conditions, in contrast to the ices II, III etc. which exist at very high pressures or low temperatures. Ice Ih possesses a stable hexagonal crystal lattice rather than a cubic one (termed ice Ic). The possibility of constructing Gibbs functions for the different high-pressure ice phases ( $>200 \mathrm{MPa}$ ) is discussed by Tchijov et al. (2008a, b).

The possibility of an extension in the form of a Gibbs function for vapor below $130 \mathrm{~K}$ has recently been discussed by Feistel and Wagner (2007) and Riethmann et al. (2008) and will be implemented in the forthcoming source code library (Feistel et al., 2009; Wright et al., 2009).

More as a theoretical concept than a practical algorithm, a Gibbs function for seawater was described by Fofonoff (1962). During the development of the International Equation of State of Seawater (EOS-80), apparently no attempt was made to combine the theoretical concept with the available data to build such a thermodynamic potential, even though all necessary properties were quantitatively available before 1980. Separate correlation equations for the density, heat capacity, sound speed and freezing temperature were derived and adopted as the new standard for oceanography (Fofonoff and Millard, 1983), and they still remain as the international standard after nearly three decades.

Additional thermal and colligative properties published by Millero and Leung (1976) were used in combination with the EOS-80 equations for the construction of the first Gibbs function of seawater (Feistel, 1993). Feistel and Hagen (1995) improved this function by including additional data, e.g. for the sound speed and the temperatures of maximum density, and conversion to ITS-90. Properties such as entropy and enthalpy that are available from this formulation in a consistent form are of growing interest for more accurate ocean models (McDougall, 2003; McDougall et al., 2003; Griffies et al., 2005; Jackett et al., 2006; Tailleux, 2008; McDougall et al., 2008).

After the appearance of the fundamental paper of Wagner and Pruß (2002), a systematic improvement of the Gibbs function of seawater proved possible by replacing pure-water properties of the Gibbs function of Feistel and Hagen (1995) by those computed from IAPWS-95 (Feistel, 2003). The related source code for seawater can be found in the digital supplement of Feistel (2005), and with the same mathematical structure but improved coefficients in Feistel et al. (2008).

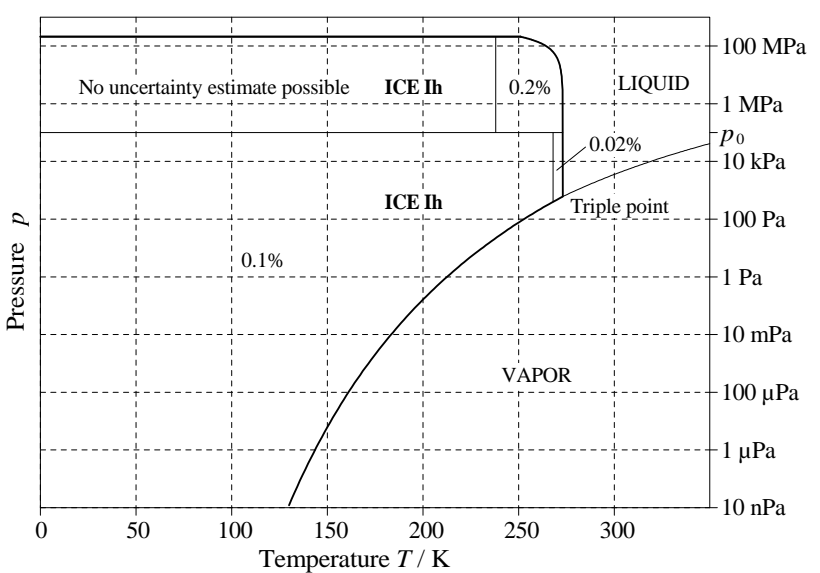

Fig. 2. Range of validity, shown in bold, and uncertainty of ice density in the IAPWS-06 formulation. The Gibbs function of ice remains valid at pressures even below the range shown here (it can be extrapolated to negative pressures to represent the effects of tensile stress), but the validity of IAPWS-95 for water vapor ends at $T=130 \mathrm{~K}$ and hence does not extend below $p=10 \mathrm{nPa}$.

The 2008 extension to high salinity and temperature for thermal and colligative properties, which became possible with the introduction of the new Reference-Composition Salinity Scale, was adopted by IAPWS (2008) and is expected to be adopted, too, as a new international oceanographic standard to replace EOS-80 (Millero et al., 2008; Feistel, 2008; McDougall et al., 2009a, b), in conjunction with IAPWS-95 for fluid water and IAPWS-06 for ice. This is the first formulation developed cooperatively by IAPWS for general applications and by the SCOR/IAPSO Working Group 127 for oceanography, being fully consistent in its pure-water properties. The range of validity of the IAPWS- 08 formulation for seawater is shown in Fig. 3. A publication that will contain a source code library including this latest version is in preparation (Feistel et al., 2009; Wright et al., 2009; McDougall et al., 2009b).

The range of validity shown in Fig. 3 is additionally constrained by precipitation or degassing of sea salt constituents from the solution. The related boundaries as functions of temperature, pressure and salinity are not yet sufficiently known; for selected components of sea salt they are reviewed by Marion et al. $(2008 \mathrm{a}, \mathrm{b})$. His results indicate that the region F in Fig. 3 is beyond a boundary at which calcium minerals precipitate out of solution due to significant supersaturation; this region should thus be treated with appropriate caution.

The three individual thermodynamic potentials for fluid water, for ice, and for the saline contribution for seawater were constructed from separate and independent experimental data sets. The integrity of this comprehensive new formulation, consisting of three independent potential functions, is superior to that of the former EOS-80 in two important ways. 


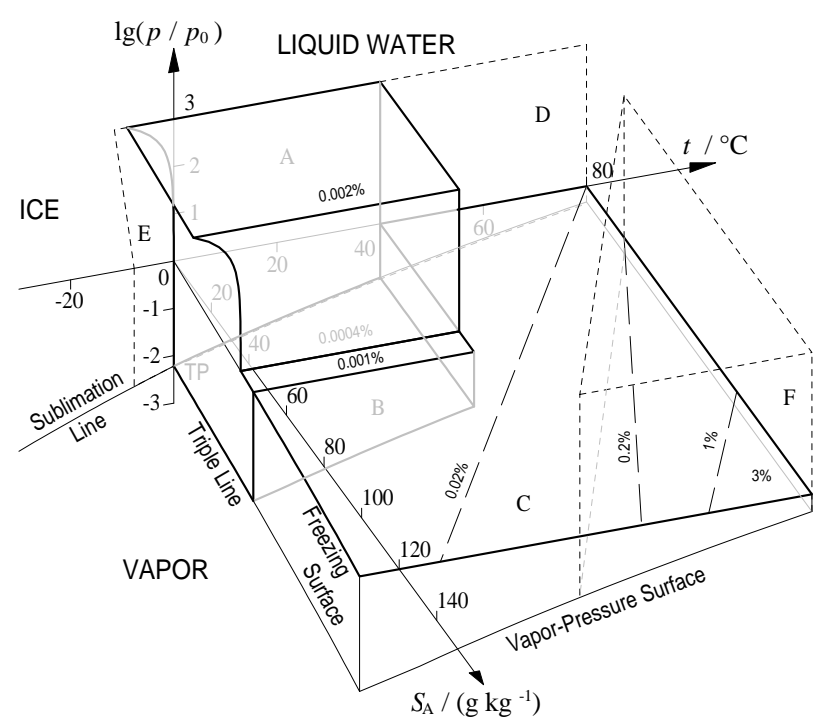

Fig. 3. Range of validity, shown in bold, and uncertainty of seawater density in the IAPWS formulation 2008 on seawater. The indicated regions are A: oceanographic standard range, B: extension to higher salinity at low pressure, C: extension to concentrated and hot brines at atmospheric pressure, D: IAPWS-95 pure-water part, E: extension of IAPWS-95 to the metastable liquid, F: range of unreliable extrapolated density derivatives. The region $\mathrm{F}$ is beyond the precipitation boundary of calcium minerals (Marion et al., 2008a, b) and is thus strictly beyond the range in which the Reference Composition (Millero et al., 2008) provides a best estimate of the seawater composition. The plane $S_{\mathrm{A}}=0$ is shown in Figs. 1, 2 and 4 with more details.

First, individual correlation equations for particular properties of water, ice and seawater have been consistently combined into compact functions, the thermodynamic potentials. Second, these independent potential functions can, in turn, be combined consistently, providing not only the properties of the particular phases/components, but also of their mutual combinations and transitions. This family of thermodynamic potentials is conveniently structured in such a way that it obeys three general conditions that are highly desirable for proper axiomatic systems. It is consistent, i.e., the possibility of deducing two different formulas for the same property is excluded, independent, i.e., no formula can be deduced from other ones, and complete, i.e., a formula is provided for every thermodynamic property.

Since thermodynamic experiments can reveal only changes of entropy or energy, the values of the absolute energy and the absolute entropy for each component, including water in liquid, gas or solid phase as well as sea salt, are freely adjustable (Fofonoff, 1962). To achieve consistency between the potential functions, both the absolute energy and entropy of each substance must take the same values independent of the particular phase or mixture of this substance. This is commonly achieved by specifying refer- ence state conditions, as described in the following section. Proper adjustment of the coefficients determining these reference conditions is also discussed.

\section{Reference states}

For fluid water, the traditional reference state condition is vanishing entropy and internal energy of the liquid phase at the solid-liquid-gas triple point of pure water. To unambiguously implement this condition in numerical models, the triple point itself must be exactly defined by mathematical equations. In implementations of IAPWS-95 and IAPWS06 , this had not always been done sufficiently rigorously or consistently, and thus requires a meticulous reconsideration, as discussed below.

First, note that the ITS-90 scale defines the kelvin temperature unit by setting the temperature value at the triple point of water to be exactly $273.16 \mathrm{~K}$ (Preston-Thomas, 1990).

The common physical triple point of water is the thermodynamic equilibrium state between liquid water, water vapor and ice. The standard definition of pure water is Vienna Standard Mean Ocean Water, VSMOW, consisting of several isotopes of hydrogen and oxygen as found under ambient conditions (IAPWS, 2008). Because these isotopes fractionate slightly differently among the equilibrated phases, instead of a unique triple "point" one effectively has a mixture in which the equilibrium temperature depends on the relative amounts of the phases (Nicholas et al., 1996; White et al., 2003). The interval over which the equilibrium temperatures can vary has been estimated to be approximately $14 \mu \mathrm{K}$ (Nicholas et al., 1996). There is therefore a fundamental uncertainty of this magnitude in ITS-90 temperature measurement at the triple point, even though a thermometer's precision in resolving temperature differences may be smaller. In practice, other experimental factors introduce additional uncertainties; Rudtsch and Fischer (2008) give $29 \mu \mathrm{K}$ as a typical combined standard uncertainty for calibration of a standard platinum resistance thermometer at the triple point of water. The value of $40 \mu \mathrm{K}$ reported by Feistel and Wagner (2006) overestimates the uncertainty.

The experimental triple-point pressure, i.e., the vapor pressure of pure water at $273.16 \mathrm{~K}$, was determined by Guildner et al. (1976) as $p_{\mathrm{t}}=611.657(10) \mathrm{Pa}$. The digits in parentheses are the combined standard uncertainty of the last two digits of the quoted value, as described by the "International System of Units (SI)" (BIPM, 2006; p. 133).

The numerical IAPWS-95 triple point is defined mathematically by equal chemical potentials and pressures of liquid water and vapor at exactly $273.16 \mathrm{~K}$.

The numerical IAPWS-95/06 triple point can be defined mathematically by equal chemical potentials of liquid water, water vapor and ice Ih, where liquid and vapor are described by IAPWS-95 and ice is described by IAPWS-06. 
From a practical point of view, all triple-point definitions discussed above and in related IAPWS publications are consistent with each other within their experimental uncertainties and natural physical fluctuations. Numerically, however, the related values are slightly different. In this paper, the numerical IAPWS-95 triple-point results were used as the definite reference point required for the consistent adjustment of free parameters in the other formulations.

Before considering details of the above defined triple points, we mention two problems that have arisen with the implementation of IAPWS-95:

(i) In order that the defined reference values of vanishing internal energy and entropy in the liquid phase at the triple point are accurately reproduced, it has been recommended that the parameters $n_{1}^{\circ}$ and $n_{2}^{\circ}$ specified in the formulation of IAPWS-95 be individually adjusted for the particular software implementation and hardware configuration. While such a procedure is essentially correct, its application was often either overlooked or ignored. Recent tests have suggested that this adjustment phase is not essential if IAPWS-95 is implemented as given in the Release but with modified values of $n_{1}^{\circ}$ and $n_{2}^{\circ}$ as given below.

(ii) Implementations should refrain from rounding of coefficients and employ the full accuracy of the official formulation that has parameters given to 14 significant figures, in conjunction with new values of $n_{1}^{\circ}$ and $n_{2}^{\circ}$ to be given in a future updated version of Table 4 of IAPWS (1996); to the accuracy quoted, these values are consistent with those given below.

The properties of the numerical IAPWS-95 triple point have been computed from two different quadruple-precision (128-bit) implementations of IAPWS-95 made independently by two of us. One result for the numerical IAPWS-95 triple point was based on code, referred to as the Wagnerand-Pruß code, made available to our group by W. Wagner and recently published in Feistel et al. (2008). The numerical precision of the code was increased to 128-bit accuracy using the double-double precision system developed and made available by Bailey et al. (2008). Error tolerances of numerical iteration procedures were reduced to the point that further reductions made no difference to our results. All coefficients were expressed to the full number of digits given in IAPWS (1996). In this implementation, the coefficients $n_{1}^{\circ}$ and $n_{2}^{\circ}$ of the IAPWS-95 formulation were adjusted to the reference-point conditions of vanishing entropy and internal energy of the liquid phase at the triple point determined by an iterative routine available in the original code obtained from Wagner. The results are given in Table 1 .

The second version of the code, referred to as the NIST code, was independently implemented at the National Institute of Standards and Technology by modifying the Fortran code of Harvey et al. (2004). Compiler options available in
Table 1. The precise values of the adjustable coefficients of IAPWS-95 (pure fluid water), IAPWS-06 (pure ice) and IAPWS-08 (saline component of seawater) obtained from quadruple-precision code implementations. These coefficients were determined by ensuring the equality of the chemical potentials of liquid water, water vapor and of ice at the triple point, as well as the conditions Eq. $(4 a, b)$ for the saline part, as discussed in the section "Reference States". The underlining in this table represents the accuracy with which these arbitrary adjustable constants can be determined by this procedure using double-precision code. In this paper when double-precision code (as opposed to quadruple-precision code) has been used to evaluate the thermodynamic properties of water ice and seawater, the arbitrary constants of this table have not been recomputed but rather the quadruple-precision determined values have been rounded to 15 significant figures and then used in the double-precision code. Note that this procedure gives more accurate values of some of these adjustable constants than can be obtained by evaluating them in double precision.

\begin{tabular}{|c|c|}
\hline Coefficient & Value \\
\hline \multicolumn{2}{|r|}{ Pure Water } \\
\hline $\begin{array}{l}n_{1}^{\circ} \\
n_{2}^{\circ}\end{array}$ & $\begin{array}{r}-\underline{8.320446483749} 693022547976804526 \\
\underline{6.683210527593} 225852567901929071\end{array}$ \\
\hline \multicolumn{2}{|r|}{ Ice } \\
\hline$g_{00}$ & $-\underline{632020.2333358855583003265002348}$ \\
\hline \multicolumn{2}{|r|}{ Seawater } \\
\hline$g_{200}$ & $\underline{1416.276484841969852362862563056}$ \\
\hline$g_{210}$ & $\underline{168.072408311} 5448863662591892666$ \\
\hline
\end{tabular}

the Lahey/Fujitsu Fortran 95 compiler ${ }^{1}$ were used to promote all 64-bit real variables to 128-bit real variables and convergence tolerances were reduced until no change was observed to the desired number of digits. The quadruple-precision values of coefficients $n_{1}^{\circ}$ and $n_{2}^{\circ}$ determined from the Wagnerand-Pruß code (Table 1) were used.

Properties at the IAPWS-95 triple point, determined using the quadruple-precision codes described above, are given in Table 2 to the number of digits to which the two implementations agree.

The properties of the numerical IAPWS-95/06 triple point have also been computed from a quadruple-precision implementation of IAPWS-95 and IAPWS-06, as discussed below.

If $(T, p)$ is a good initial approximation to the numerical IAPWS-95/06 triple point (e.g., $T=273.16 \mathrm{~K}, p=611.655 \mathrm{~Pa}$ as reported by Wagner and Pruß, 2002), an iterative improvement can be obtained from the linearized equations

$g^{\text {Ih }}-s^{\text {Ih }} \Delta T+v^{\text {Ih }} \Delta p=g^{\mathrm{W}}-s^{\mathrm{W}} \Delta T+v^{\mathrm{W}} \Delta p$

\footnotetext{
${ }^{1}$ Certain commercial products are identified in this paper, but only in order to adequately specify the procedure. Such identification neither constitutes nor implies recommendation or endorsement by any of the organizations represented by the authors.
} 
Table 2. Numerical results for properties at the IAPWS-95 triple point obtained from quadruple-precision implementations. Here, $g$ is the specific Gibbs energy and $\rho$ the density of liquid water (superscript W) and vapor (Vap). The underlined numbers indicate the digits that, based on our tests, can reasonably be expected to be reproduced using double-precision code.

\begin{tabular}{|c|c|c|}
\hline Property & Value & Unit \\
\hline$T$ & 273.16 & $\mathrm{~K}$ \\
\hline$p^{\mathrm{W}}$ & $611.6547710078944264442598 \times 10^{-6}$ & $\mathrm{MPa}$ \\
\hline$p^{\text {Vap }}$ & $611.6547710078944264442598 \times 10^{-6}$ & $\mathrm{MPa}$ \\
\hline$g^{\mathrm{W}}$ & 0.6117817034563826236673 & $\mathrm{~J} \mathrm{~kg}^{-1}$ \\
\hline$g$ Vap & 0.6117817034563826236673 & $\mathrm{~J} \mathrm{~kg}^{-1}$ \\
\hline$\rho^{\mathrm{W}}$ & $\overline{999.792520} 031620646603898354735$ & $\mathrm{~kg} \mathrm{~m}^{-3}$ \\
\hline$\rho^{\text {Vap }}$ & $\overline{4.854575724778} 588417176210 \times 10^{-3}$ & $\mathrm{~kg} \mathrm{~m}^{-3}$ \\
\hline
\end{tabular}

$g^{\text {Ih }}-s^{\text {Ih }} \Delta T+v^{\text {Ih }} \Delta p=g^{\text {Vap }}-s^{\text {Vap }} \Delta T+v^{\text {Vap }} \Delta p$,

which have the solution

$$
\begin{gathered}
\Delta T=\frac{\left(g^{\mathrm{Ih}}-g^{\mathrm{W}}\right)\left(v^{\mathrm{Vap}}-v^{\mathrm{Ih}}\right)-\left(g^{\mathrm{Ih}}-g^{\mathrm{Vap}}\right)\left(v^{\mathrm{W}}-v^{\mathrm{Ih}}\right)}{\left(s^{\mathrm{Ih}}-s^{\mathrm{W}}\right)\left(v^{\mathrm{Vap}}-v^{\mathrm{Ih}}\right)-\left(s^{\mathrm{Ih}}-s^{\mathrm{Vap}}\right)\left(v^{\mathrm{W}}-v^{\mathrm{Ih}}\right)} \\
\Delta p=\frac{\left(s^{\mathrm{Ih}}-s^{\mathrm{W}}\right)\left(g^{\mathrm{Ih}}-g^{\mathrm{Vap}}\right)-\left(s^{\mathrm{Ih}}-s^{\mathrm{Vap}}\right)\left(g^{\mathrm{Ih}}-g^{\mathrm{W}}\right)}{\left(s^{\mathrm{Ih}}-s^{\mathrm{W}}\right)\left(v^{\mathrm{Vap}}-v^{\mathrm{Ih}}\right)-\left(s^{\mathrm{Ih}}-s^{\mathrm{Vap}}\right)\left(v^{\mathrm{W}}-v^{\mathrm{Ih}}\right)} .
\end{gathered}
$$

Here, $g$ is the specific Gibbs energy, $s$ the specific entropy and $v$ the specific volume of ice (superscript Ih), liquid water (W) and vapor (Vap). Use of this iterative approach to determine successive improvements allows one to determine the numerical triple-point temperature and pressure values corresponding to the parameter values listed in the Releases. When this is done using quadruple-precision calculations, we find that $T_{\mathrm{t}}=273.1600000930708556675161234 \mathrm{~K}$ and $p_{\mathrm{t}}=611.65477514454513119209852 \times 10^{-6} \mathrm{MPa}$.

The deviation (almost $0.1 \mu \mathrm{K}$ ) of the above estimate of the triple-point temperature from $273.16 \mathrm{~K}$ shows that a small modification of the adjustable coefficient $g_{00}$ of the ice formulation IAPWS-06 is required for consistency with the ITS-90 temperature scale at this level of precision. Starting again with $T=273.16 \mathrm{~K}$, and using Eq. (1a, b) to iteratively adjust $\Delta p$ and $g^{\text {Ih }}$ with $\Delta T=0$, we find that the value $g_{00}=-0.632020233449497 \times 10^{6}$ published for the Gibbs function of ice (Feistel and Wagner, 2006; IAPWS, 2006), must be adjusted to $g_{00}=-0.632020233335886 \times 10^{6}$ to correct the numerical IAPWS-95/06 triple-point temperature from the value given above to $T=273.160000000000 \mathrm{~K}$ in all 15 digits. This new value for $g_{00}$ is expected to be included in a future revised version of IAPWS-06. The more precise quadruple-precision estimate of $g_{00}$ is given in Table 1.
Determination of $g_{00}$ completes the consistent determination of all coefficients involved in the potential functions for pure water. The triple-point properties of all three water phases were computed in quadruple precision after adjustment of the coefficients $n_{1}^{\circ}, n_{2}^{\circ}$ and $g_{00}$, and are reported in Table 3. These results are given to the full precision for which stable results between iterations are obtained on one particular platform. Slight differences may occur on other platforms. Note that we use the full quadruple-precision coefficients in Table 3 and in all of the tables presented in the appendix. The values presented are thus our best estimates of the true solutions, but will not be precisely reproduced by double-precision implementations. Underlining has thus been used in the tables given in this paper to indicate the digits that are expected to be reproduced by double-precision implementations. A discussion of the methods used to estimate what precision is achievable with double-precision implementations is given in the appendix.

It remains to allow for the influence of sea salt in seawater. In the seawater formulation (Feistel, 2008; IAPWS, 2008), the Gibbs function, $g$, of seawater is expressed as a sum of a water part, $g^{\mathrm{W}}$, derived from the IAPWS-95 Helmholtz potential, and a saline part, $g^{\mathrm{S}}$, as,

$g\left(S_{\mathrm{A}}, T, p\right)=g^{\mathrm{W}}(T, p)+g^{\mathrm{S}}\left(S_{\mathrm{A}}, T, p\right)$

The function $g^{\mathrm{W}}(T, p)$ is related to the Helmholtz potential $f^{\mathrm{W}}\left(T, \rho^{\mathrm{W}}\right)$ by the relation

$g^{\mathrm{W}}(T, p)=f^{\mathrm{W}}\left(T, \rho^{\mathrm{W}}\right)+\rho^{\mathrm{W}}(T, p) \times f_{\rho}^{\mathrm{W}}\left(T, \rho^{\mathrm{W}}\right)$

where the subscript $\rho$ on $f^{\mathrm{W}}$ indicates partial differentiation with $T$ constant and

$\rho^{\mathrm{W}}(T, p)=\rho\left(S_{\mathrm{A}}=0, T, p\right)$

The salinity argument of the Gibbs function in Eq. (3) is the Absolute Salinity $S_{\mathrm{A}}$, which is the mass of dissolved material in seawater per unit mass of solution. For seawater of Reference Composition, Absolute Salinity is the same as the Reference-Composition Salinity (Millero et al., 2008).

It is convenient to adjust the free parameters determining the reference levels of absolute energy and absolute entropy of sea salt such that entropy and enthalpy of seawater vanish for the standard ocean state $\left(p_{\mathrm{SO}}=101325 \mathrm{~Pa}\right.$, $\left.T_{\mathrm{SO}}=273.15 \mathrm{~K}, S_{\mathrm{SO}}=35.16504 \mathrm{~g} \mathrm{~kg}^{-1}\right)$. The related adjustable coefficients of the Gibbs function of seawater are $g_{200}$ and $g_{210}$, i.e., its pressure-independent terms proportional to salinity and to the powers 0 and 1 in temperature (Fofonoff, 1962; Feistel, 2003; IAPWS, 2008).

At its meeting in Warnemünde, Germany, in May 2006, WG127 chose to specify the arbitrary constants corresponding to the saline specific entropy, $s$, and the saline specific enthalpy, $h^{\mathrm{S}}$, at the standard ocean state as

$$
\begin{aligned}
& s^{\mathrm{S}}\left(S_{\mathrm{SO}}, T_{\mathrm{SO}}, p_{\mathrm{SO}}\right)=s^{\mathrm{W}}\left(T_{\mathrm{t}}, p_{\mathrm{t}}\right)-s^{\mathrm{W}}\left(T_{\mathrm{SO}}, p_{\mathrm{SO}}\right) \\
& h^{\mathrm{S}}\left(S_{\mathrm{SO}}, T_{\mathrm{SO}}, p_{\mathrm{SO}}\right)=u^{\mathrm{W}}\left(T_{\mathrm{t}}, p_{\mathrm{t}}\right)-h^{\mathrm{W}}\left(T_{\mathrm{SO}}, p_{\mathrm{SO}}\right) .
\end{aligned}
$$


Table 3. Quadruple-precision results for the properties of water, vapor and ice at the quadruple-precision estimate of the IAPWS-95 triple point given in Table $2\left(T=273.16 \mathrm{~K}, p=611.6547710078944264442598 \times 10^{-6} \mathrm{MPa}\right)$, computed with the coefficients given in Table 1 of this paper. The underlined numbers indicate the digits that, based on our tests, can reasonably be expected to be reproduced using double-precision code.

\begin{tabular}{|c|c|c|c|c|}
\hline Property & Property of water & Property of vapor & Property of ice & Unit \\
\hline$g$ & $6.1178170345638262367 \mathrm{E}-1$ & $6.1178170345638262367 \mathrm{E}-1$ & $6.1178170345638262367 \mathrm{E}-1$ & $\mathrm{~J} \mathrm{~kg}^{-1}$ \\
\hline$(\partial g / \partial T)_{p}$ & $-2 . \mathrm{E}-27^{\mathrm{a}}, 5 . \mathrm{E}-11^{\mathrm{a}}$ & $-9.1554934092985614572 \mathrm{E}+3$ & $1.2206943393964807369 \mathrm{E}+3$ & $\mathrm{~J} \mathrm{~kg}^{-1} \mathrm{~K}^{-1}$ \\
\hline$(\partial g / \partial p)_{T}$ & $1.0002075230252500703 \mathrm{E}-3$ & $2.0599122491710824907 \mathrm{E}+2$ & $1.0908581273666870118 \mathrm{E}-3$ & $\mathrm{~m}^{3} \mathrm{~kg}^{-1}$ \\
\hline$\left(\partial^{2} g / \partial T^{2}\right)_{p}$ & $-1.5448497277676153768 \mathrm{E}+1$ & -6.8983454098615831310 & -7.6760298587519086996 & $\mathrm{~J} \mathrm{~kg}^{-1} \mathrm{~K}^{-2}$ \\
\hline$\left(\partial^{2} g / \partial T \partial p\right)$ & $-6.7979215180919329145 \mathrm{E}-8$ & $7.5819292780093068933 \mathrm{E}-1$ & $1.7438796470007613398 \mathrm{E}-7$ & $\mathrm{~m}^{3} \mathrm{~kg}^{-1} \mathrm{~K}^{-1}$ \\
\hline$\left(\partial^{2} g / \partial p^{2}\right)_{T}$ & 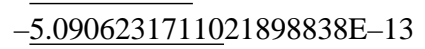 & $-3.3699243312745608812 \mathrm{E}-1$ & $-1.2849594157169302559 \mathrm{E}-13$ & $\mathrm{~m}^{3} \mathrm{~kg}^{-1} \mathrm{~Pa}^{-1}$ \\
\hline$h$ & $6.1178170345638262367 \mathrm{E}-1$ & $2 . \overline{5009151914656985040 \mathrm{E}+6}$ & $-\overline{3.3344425396783922172 \mathrm{E}+5}$ & $\mathrm{~J} \mathrm{~kg}^{-1}$ \\
\hline$f$ & $4 . \mathrm{E}-26^{\mathrm{a}}, 5 . \mathrm{E}-9^{\mathrm{a}}$ & $-1.2599490372460606626 \mathrm{E}+5$ & $-5.5446874640188852815 \mathrm{E}-2$ & $\mathrm{~J} \mathrm{~kg}^{-1}$ \\
\hline$u$ & 7.E-25 ${ }^{\mathrm{a}}, 2 . \mathrm{E}-9^{\mathrm{a}}$ & $2.3749196759593889814 \mathrm{E}+6$ & $-3.3344492119641731829 \mathrm{E}+5$ & $\mathrm{~J} \mathrm{~kg}^{-1}$ \\
\hline$s$ & 2.E $-27^{\mathrm{a}},-5 \cdot \mathrm{E}-11^{\mathrm{a}}$ & $9.1554934092985614572 \mathrm{E}+3$ & $-1.2206943393964807369 \mathrm{E}+3$ & $\mathrm{~J} \mathrm{~kg}^{-1} \mathrm{~K}^{-1}$ \\
\hline$\rho$ & $9.9979252003162064660 \mathrm{E}+2$ & $4.8545757247785884172 \mathrm{E}-3$ & $9.1670949219948795011 \mathrm{E}+2$ & $\mathrm{~kg} \mathrm{~m}^{-3}$ \\
\hline$c_{p}$ & $4.2199115163700181633 \mathrm{E}+3$ & $1.8843520321577900481 \mathrm{E}+3$ & $2.0967843162166713804 \mathrm{E}+3$ & $\mathrm{~J} \mathrm{~kg}^{-1} \mathrm{~K}^{-1}$ \\
\hline$\alpha$ & $-6.7965110855503138742 \mathrm{E}-5$ & $3.6807049820012030606 \mathrm{E}-3$ & $1.5986310256590902275 \mathrm{E}-4$ & $\mathrm{~K}^{-1}$ \\
\hline$\kappa_{T}$ & $5.0895669687676183977 \mathrm{E}-10$ & $\overline{1.63595528529462} 01284 \mathrm{E}-3$ & $1.1779344934788178705 \mathrm{E}-10$ & $\mathrm{~Pa}^{-1}$ \\
\hline$\kappa_{s}$ & $\overline{5.08657624752} 61953085 \mathrm{E}-10$ & 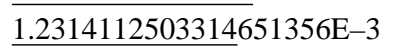 & $1.1416159777876331107 \mathrm{E}-10$ & $\mathrm{~Pa}^{-1}$ \\
\hline
\end{tabular}

${ }^{\text {a }}$ Each of these numbers is identically zero in the theoretical model. The numbers shown here give the roundoff errors corresponding to quadruple- and double-precision implementations, respectively.

NOTE: The notation $y \mathrm{E} \pm n$ should be interpreted as $y \times 10^{ \pm n}$.

Here, $u^{\mathrm{W}}, h^{\mathrm{W}}$ and $s^{\mathrm{W}}$ are the specific internal energy, enthalpy and entropy of liquid water of the IAPWS-95 formulation, respectively, and $\left(T_{\mathrm{t}}, p_{\mathrm{t}}\right)$ refers to the numerical IAPWS-95 triple point as in Table 2. IAPWS-95 specifies the reference state conditions $s^{\mathrm{W}}\left(T_{\mathrm{t}}, p_{\mathrm{t}}\right)=0$ and $u^{\mathrm{W}}\left(T_{\mathrm{t}}, p_{\mathrm{t}}\right)=0$. The values of $g_{200}$ and $g_{210}$ determined by Eq. (4) are given in Table 1 and numerical values of the quantities referred to in these equations are reported in additional tables in the appendix.

The definitions Eq. (4a, b) have the following properties:

1. the free constants of the saline Gibbs energy, $g^{\mathrm{S}}$, are specified, rather than those of the complete Gibbs energy, $g$, of seawater,

2. the reference state definitions Eq. (4a, b) impose no conditions on the IAPWS-95 formulation,

3. the definitions Eq. (4a, b) require no additional explicit numerical values to be given,

4. the right sides of Eq. (4a, b) are independent of the choice of the two free constants within IAPWS-95, and so are the saline quantities $s^{\mathrm{S}}\left(S_{\mathrm{SO}}, T_{\mathrm{SO}}, p_{\mathrm{SO}}\right)$ and $h^{\mathrm{S}}\left(S_{\mathrm{SO}}, T_{\mathrm{SO}}, p_{\mathrm{SO}}\right)$. In other words, the IAPWS reference state definition imposes no conditions on the formulation, $g^{\mathrm{S}}(S, T, p)$,

5. the definitions are different from those given in Feistel (2003) only by the tiny misfit of $g\left(0, T_{\mathrm{SO}}, p_{\mathrm{SO}}\right)$ from
Feistel (2003) to $g^{\mathrm{W}}\left(T_{\mathrm{SO}}, p_{\mathrm{SO}}\right)$ from IAPWS-95, thus being comfortably consistent for oceanographers, and

6 . the numerical absolute values of $s\left(S_{\mathrm{SO}}, T_{\mathrm{SO}}, p_{\mathrm{SO}}\right)$ and $h\left(S_{\mathrm{SO}}, T_{\mathrm{SO}}, p_{\mathrm{SO}}\right)$ for seawater depend on the IAPWS95 reference state in the same way as do $s^{\mathrm{W}}\left(T_{\mathrm{t}}, p_{\mathrm{t}}\right)$ and $u^{\mathrm{W}}\left(T_{\mathrm{t}}, p_{\mathrm{t}}\right)$ from IAPWS-95.

The properties of liquid water, ice and seawater at the standard ocean state were computed in quadruple precision and are reported to 20 significant figures in Table A8 of the appendix.

We note that, in all of our tables, we have reported results to much higher precision than could be justified by the constraints available from experimental data. To explain why we have done this, it is necessary to clearly distinguish between mathematical formulations, practical implementations and the representation of experimental data. Formulations such as IAPWS-95, IAPWS-06 or IAPWS-08 are mathematical models of the reality that provide precise descriptions of all thermodynamic properties in their particular scope. Although the agreement with reality is required only to the uncertainty of the experimental data, the mathematical models used to approximate the data are precisely defined constructs. Implementations, on the other hand, possess numerical uncertainties depending on the hardware and software of the implementation platform, on the way the program flow is organized in the code, on the syntax permitted by the 
programming language, and on the way this code is executed by compilers or interpreters. There can of course be different implementations of the same mathematical model. They are all only approximations of the precise mathematical models that they represent, but their numerical errors should be negligibly small compared to the uncertainties of the experimental data.

Things become more complicated when more than one formulation is considered and mutual consistency is required, as in the case of fluid water, ice and seawater. Although the mathematical models may be formulated to be exactly consistent, if the reference-point properties of ice are determined from an arbitrary implementation of fluid water properties and used as part of the mathematical model, then the theoretical formulation for ice becomes implementation-dependent rather than mathematically exact. If further formulations are integrated this way into a family of formulations, this procedure may eventually lead to significant inconsistencies within that family. Whether or not these inconsistencies are significant will depend on the accuracy used to determine all parameters that are determined based on consistency requirements.

To consider a simple illustration, we imagine the following situation. The Gibbs function $g(T, p)$ of liquid water is given (e.g., computed from IAPWS-95). To obtain a fast implementation, we develop separate correlation equations (i.e., mathematical models in our terminology) for each of its partial derivatives $g, g_{T}, g_{p}, g_{T T}, g_{T p}$ and $g_{p p}$. We only require that these correlation equations agree with the original formulation within the experimental uncertainty of entropy, density, etc. Using this approach, we will very probably arrive at a situation where our simplified separate equations in their combination no longer reproduce, say, the sound speed of the original formulation within its uncertainty.

The conclusion from these considerations is that the consistency between different but related formulations should always be as precise as possible, in the ideal case mathematically exact. If this consistency can be specified only numerically, then the required relations should be computed with the highest achievable accuracy rather than within experimental uncertainty only. In particular, the fundamental mutual anchor points that impose consistency between the formulations should be very precisely determined in order to avoid unpredictable consequences for quantities derived from arbitrary combinations of those formulations.

There are two different methods whereby this requirement for rigorous consistency can be realized: the static and the dynamic definition of the adjustable coefficients. In the static method, the coefficients are computed based on the reference-state conditions with a high precision in advance, and the result of this computation is given as an explicit numerical value for each coefficient. The advantage of this method is that all implementations will use an identical set of coefficients, and the algorithms for fluid water, ice, and the saline part of seawater can be implemented as modules independent of each other.

In the dynamic method, the adjustable coefficients are defined by the reference-state conditions in the form of equations rather than their solutions. These equations will be solved numerically during the run-time initialization of each particular implementation, leading to slightly implementation-dependent values of the adjustable coefficients which most accurately obey the conditions on the given platform.

For the quadruple-precision implementation used to compute the tables in the appendix, we have necessarily applied the dynamic method. However, given that the resulting coefficients are very accurately determined and have been carefully verified, we recommend that the static values with 15 significant figures, obtained by rounding the coefficients given in Table 1, be used in future work with doubleprecision code. This is already the recommendation for the Releases IAPWS-06 and IAPWS-08. We recommend that this approach also be taken for IAPWS-95 with coefficients determined from Table 1 . This approach will be taken in the forthcoming source-code library (Feistel et al., 2009; Wright et al., 2009; McDougall et al., 2009b), where we will take all coefficients to be consistent with Table 1; this consistent set of coefficients is expected to be adopted by IAPWS in 2009 as minor revisions to the IAPWS-95 and IAPWS-06 releases. This approach provides the most accurate coefficients currently available, the best possible consistency at the reference states obtainable with static values of all coefficients, and it will ensure that any inconsistencies between the results from different implementations are due to the details of the implementation or the platform used to do the calculations, and not due to differences in the specification of coefficients. Tests reveal that differences between results on different platforms obtained using static coefficients should be entirely negligible from a practical point of view.

Finally, we note that the mutually consistent family of formulations for water, ice and seawater will likely grow further in the future. Possible candidates are descriptions of aqueous sodium chloride solutions, of solid sea salt components and their saturation and precipitation from seawater, properties of humid air or gases dissolved in water, and the surface tension and refractive index of seawater. There will certainly be a demand to consistently link such formulations to the existing family. This will require highly accurate reference-state properties to be used for the determination of the coefficients of the added formulations. For this purpose, we provide in this paper tables of highly accurate reference values.

As an example of a potential need for such accuracy, one may at some future time wish to consider components of sea salt such as $\mathrm{NaCl}$ or $\mathrm{CO}_{2}$ in order to describe their individual properties in a solid or gas state or aqueous solution. Their absolute energies and entropies can conveniently be specified then to be consistent with the absolute energy and entropy of seawater at the standard ocean state, using 
the Reference-Composition model (Millero et al., 2008). For components that contribute only, say, a fraction of $0.01 \%$ to the total mass of sea salt, their absolute internal energy may be defined with precision reduced by the same fraction. If the total internal energy of sea salt is available now with 15 correct digits, only 11 accurate digits will be available for such a component, since all fractions need to sum up to give exactly 1. Thus, providing 19 digits for sea salt will permit a consistent specification of those components with 15 valid digits. For the same reason, the Reference Composition of sea salt itself was defined with more valid digits than required by the experimental uncertainties of its measurements, for example, to guarantee mathematically exact electrical neutrality of the resulting electrolyte model.

\section{Metastable liquid water}

When sea salt is dissolved in water, the triple point defined by the equilibrium between seawater, ice and vapor is displaced from its pure-water locus along the sublimation line of pure water to lower pressures and temperatures (Fig. 4). As a consequence, stable liquid seawater is found at temperatures and pressures where pure water is a metastable liquid, either subcooled or superheated. Thus, to determine seawater properties as a sum of pure water plus saline contributions, the properties of water in the metastable regimes are needed.

A rough estimate of the amount by which the vapor pressure and the freezing temperature are lowered due to dissolved sea salt can be determined from the thermodynamic equilibrium conditions in the form of the first terms of the related series expansions with respect to salinity, commonly known as Raoult's laws.

The equilibrium between ice and seawater requires equal temperatures, pressures and chemical potentials of the water component in both phases, i.e.,

$g^{\mathrm{Ih}}=g^{\mathrm{W}}+g^{\mathrm{S}}-S_{\mathrm{A}}\left(\frac{\partial g^{\mathrm{S}}}{\partial S_{\mathrm{A}}}\right)_{T, p}$.

For a small depression value, $\Delta T / T$, expanding Eq. (5a) in a power series in $\Delta T$ and $S$, we obtain approximately

$\frac{\Delta T}{T} \approx-\frac{R_{\mathrm{S}} T}{h^{\mathrm{W}}-h^{\mathrm{Th}}} \times S_{\mathrm{A}} \approx-0.22 \times S_{\mathrm{A}}$.

Here, $R_{\mathrm{S}}=R / M_{\mathrm{S}}=264.7599 \mathrm{~J} \mathrm{~kg}^{-1} \mathrm{~K}^{-1}$ is the specific gas constant of sea salt, $R$ is the molar gas constant, $M_{\mathrm{S}}=31.40382 \mathrm{~g} \mathrm{~mol}^{-1}$ is the molar mass of sea salt (Millero et al., 2008), and $h^{\mathrm{W}}-h^{\mathrm{Ih}} \approx 333 \mathrm{~kJ} \mathrm{~kg}^{-1}$ is the melting enthalpy of ice. Adopted from the theory of ideal solutions (Feistel, 2008), the logarithmic term of the salinity expansion of $g^{\mathrm{S}}$ is responsible for Eq. (5b).

Similarly, the equilibrium condition between vapor and seawater,

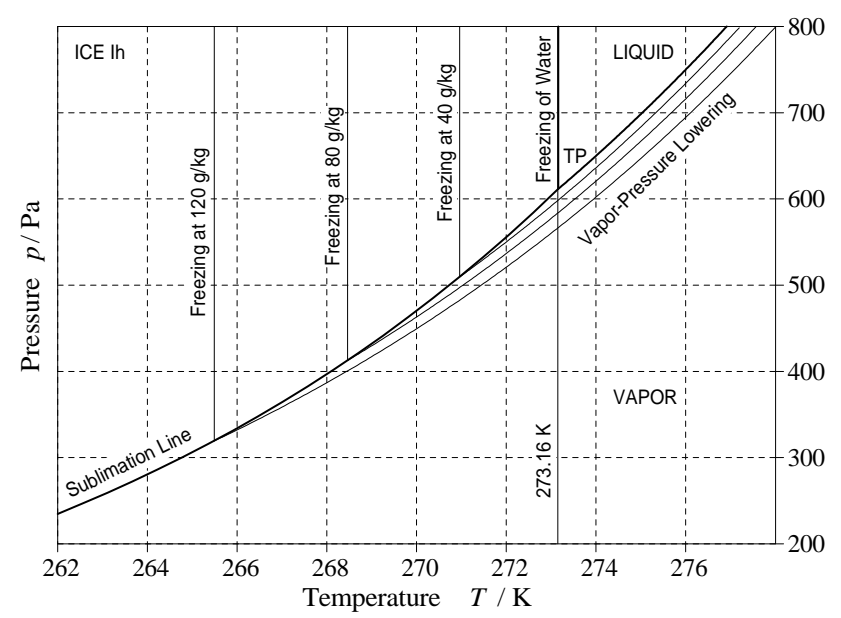

Fig. 4. Lowering of vapor pressure and of freezing temperature of seawater as a function of salinity in the vicinity of the pure-water triple point (TP). The four curves correspond to the four values of absolute salinity for which freezing temperatures are indicated on the diagram, with higher salinity values resulting in lowering of the vapor pressure for a given temperature. For non-zero salinities, the stable seawater phase occurs at temperature and salinity values for which the pure-water liquid phase is metastable. This figure is a magnified projection of Fig. 3 along the salinity axis. The projected triple line coincides with the sublimation line.

$g^{\text {Vap }}=g^{\mathrm{W}}+g^{\mathrm{S}}-S_{\mathrm{A}}\left(\frac{\partial g^{\mathrm{S}}}{\partial S_{\mathrm{A}}}\right)_{T, p}$,

gives the analogous approximation for the vapor pressure lowering, as

$\frac{\Delta p}{p} \approx-\frac{M_{\mathrm{W}}}{M_{\mathrm{S}}} \times S_{\mathrm{A}} \approx-0.57 \times S_{\mathrm{A}}$.

Here, $M_{\mathrm{W}}=18.015268 \mathrm{~g} \mathrm{~mol}^{-1}$ is the molar mass of water (IAPWS 2001).

It is evident that for our purposes the mathematical function $g^{\mathrm{W}}(T, p)$ in Eq. (3) must produce reasonable values over the entire range of validity of $g^{\mathrm{S}}\left(S_{\mathrm{A}}, T, p\right)$. Some documentation of reasonable metastable behaviour of IAPWS-95 was provided by Wagner and Pruß (2002), but an IAPWS task group was formed to investigate this issue more thoroughly and concluded in its report given at the 2007 meeting in Lucerne that:

(i) the investigations established conclusively that IAPWS95 behaves reasonably in the subcooled liquid range down to temperatures as low as $240 \mathrm{~K}$;

(ii) IAPWS-95 functions are visually and numerically smooth in the subcooled region even at high pressures;

(iii) an extensive literature search made in 2005 did not reveal any evidence for any new data in the subcooled region not already mentioned in the Wagner and Pruß (2002) paper; 
(iv) IAPWS-95 is in satisfactory agreement with existing experimental data for subcooled water (density, heat capacity, speed of sound) at normal pressure;

(v) there are no data for subcooled water at high pressures (the values discussed in some papers are computed exclusively from models or extrapolation); and

(vi) there is no better option than IAPWS-95 as the pure water reference for the seawater formulation.

Regarding point (v), recent density measurements below $0^{\circ} \mathrm{C}$ at high pressures (Sotani et al., 2000; Asada et al., 2002) agree with IAPWS- 95 within $0.05 \%$ over the oceanographic pressure range up to $100 \mathrm{MPa}$.

As is evident from Fig. 4, the metastable liquid range required for use in the determination of seawater properties using the form Eq. (3) extends to pressures and temperatures that are well below those corresponding to the triple point of pure water. For seawater applications, code implementing IAPWS-95 should allow consideration of the full range of property values indicated in Fig. 4, rather than being restricted to the region of the stable liquid phase. (Such an application of IAPWS-95 corresponds to an extrapolation of this formulation.) A new version of the code that allows consideration of the full range of seawater conditions of interest will be made available in Feistel et al. (2009) and Wright et al. (2009).

\section{Discussion}

The SCOR/IAPSO Working Group 127 (WG127) was formed in 2005 and charged with developing a new seawater standard for oceanography to replace the International Equation of State of Seawater (EOS-80, Fofonoff and Millard 1983) that has served the needs of oceanographers for nearly three decades. The general approach taken by WG127 has been to develop a Gibbs function formulation that can be applied over the full range of conditions of interest including pure water, seawater and sea ice.

The IAPWS-95 Helmholtz potential function (Wagner and Pruß, 2002) has served as the starting point from which the Gibbs function for pure water has been determined. This was complemented by Feistel and Wagner (2006) by the introduction of a Gibbs potential for salt-free ice, thus completing the required set of Gibbs functions for pure water, including solid, liquid and vapor phases.

The solid-liquid-gas triple point plays a special role in Gibbs function (and other) formulations of the thermodynamic properties of seawater. In particular, it serves as a reference point at which entropy and internal energy of the liquid water phase are commonly set to zero to determine two free parameters in the formulation. Once these two free parameters for the liquid phase are set, an additional free parameter that enters the formulation of the Gibbs potential for the solid phase must be chosen consistent with the definition of the ITS-90 temperature scale for which the value $273.16 \mathrm{~K}$ is defined by the triple point. A consequence of this fact is that any change in the Gibbs function for pure water that results in a change in the value of the Gibbs potential for liquid and vapor at the triple point will require an adjustment of the free parameter in the Gibbs function for the solid phase in order to retain the property that the temperature is exactly $273.16 \mathrm{~K}$ at this point.

Unfortunately, the numerical implementation of the code used by Feistel and Wagner (2006) had its parameters rounded off to slightly lower precision than those listed in the IAPWS-95 release, thus resulting in a very small but nonzero deviation from the strict IAPWS-95 definition of the Helmholtz function. While this difference results in changes that are well within measurement uncertainties, the adjustment to achieve strict consistency with IAPWS-95 results in a small inconsistency between the physical definition of the triple point and the requirement that the temperature at the triple point be $273.16 \mathrm{~K}$ on the ITS-90 temperature scale. In Sect. 3, we have thus adjusted the free parameter $g_{00}$ to very precisely satisfy this condition. To achieve highly accurate results (and much more accurate than required for consistency with observations), we have used quadruple-precision numerical code in this exercise, resulting in the adjusted value $g_{00}=-0.632020233335886 \times 10^{6}$ when rounded to double precision.

With code in precise agreement with IAPWS-95 and properly adjusted to the reference state conditions, and the correction of the parameter $g_{00}$ as required to maintain consistency with the ITS-90 temperature scale, Table 1, the Gibbs function formulation for pure water is complete and fully consistent.

To complete the Gibbs function formulation for seawater, the Gibbs potential associated with salinity effects has been determined by Feistel (2008) and added to the Gibbs potential for pure water as in Eq. (3). Use of this form for the Gibbs function of seawater ensures consistency with the Helmholtz formulation for pure water, but requires some special considerations for its application. In particular, to use Eq. (3) over the desired application range for seawater, it has been necessary to extend the range of application of the Gibbs function for pure water to temperature and pressure values for which seawater is a stable liquid, but the stable phase of pure water is ice Ih or vapor. Thus metastable states of liquid water have been examined, as discussed in Sect. 4.

An important feature of the formulation of Feistel (2008) is its applicability to thermal and colligative properties for temperatures up to $80^{\circ} \mathrm{C}$ and for salinities extending from 0 to $120 \mathrm{~g} / \mathrm{kg}$ at atmospheric pressure. This salinity range extends beyond the currently valid salinity scale PSS-78 at both low and high values. A review of the development of different salinity scales is given in Millero et al. (2008), in which a new salinity scale termed Reference-Composition Salinity is defined that does not suffer from these limitations 
Table A1. Quadruple-precision values corresponding to results published in Table 6 of IAPWS-95 with the coefficients given in Table 1 of this paper. The ideal-gas part $\phi^{\circ}$ and the residual part $\phi^{\mathrm{r}}$ of the dimensionless Helmholtz free energy together with the corresponding derivatives $^{\mathrm{a}}$ are shown for $T=500 \mathrm{~K}$ and $\rho=838.025 \mathrm{~kg} \mathrm{~m}^{-3}$. The underlined numbers indicate the digits that, based on our tests, can reasonably be expected to be reproduced using double-precision code.

\begin{tabular}{llll}
\hline$\phi^{\circ}$ & 2.047977334795977679296586756701 & $\phi^{\mathrm{r}}$ & $-\underline{3.426932056815592848942243599952}$ \\
$\phi_{\delta}^{\circ}$ & $\underline{0.3842367471137495898093732287223}$ & $\phi_{\delta}^{\mathrm{r}}$ & $\underline{-0.3643666503638817298034879725024}$ \\
$\phi_{\delta \delta}^{\circ}$ & $\underline{-0.1476378778325555537348148082081}$ & $\phi_{\delta \delta}^{\mathrm{r}}$ & $\underline{0.8560637009746113823633081128560}$ \\
$\phi_{\tau}^{\circ}$ & $\underline{9.046111061752422039021337148156}$ & $\phi_{\tau}^{\mathrm{r}}$ & $\underline{-5.814034352384169258028794246361}$ \\
$\phi_{\tau \tau}^{\circ}$ & $-\underline{1.932491850130520326231797178581}$ & $\phi_{\tau \tau}^{\mathrm{r}}$ & $-\underline{2.234407368843363755796662019232}$ \\
$\phi_{\delta \tau}^{\circ}$ & 0 & $\phi_{\delta \tau}^{\mathrm{r}}$ & $-\underline{1.121769146703061888902147087817}$ \\
\hline
\end{tabular}

${ }^{\text {a }}$ For the abbreviated notation of the derivatives of $\phi^{\circ}$ and $\phi^{\mathrm{r}}$ see the footnotes of Tables 4 and 5 of IAPWS-95, respectively.

Table A2. Quadruple-precision results for water properties in the single-phase region at the selected values of $T$ and $\rho$ published in Table 7 of IAPWS-95 with the coefficients given in Table 1 of this paper. The underlined numbers indicate the digits that, based on our tests, can reasonably be expected to be reproduced using double-precision code.

\begin{tabular}{|c|c|c|c|c|c|}
\hline $\begin{array}{l}T \\
\mathrm{~K}\end{array}$ & $\begin{array}{l}\rho \\
\mathrm{kg} \mathrm{m}^{-3}\end{array}$ & $\begin{array}{l}p \\
\mathrm{MPa}\end{array}$ & $\begin{array}{l}c_{v} \\
\mathrm{~J} \mathrm{~kg}^{-1} \mathrm{~K}^{-1}\end{array}$ & $\begin{array}{l}w \\
\mathrm{~m} \mathrm{~s}^{-1}\end{array}$ & $\begin{array}{l}s \\
\mathrm{~J} \mathrm{~kg}^{-1} \mathrm{~K}^{-1}\end{array}$ \\
\hline \multirow[t]{3}{*}{300} & 996.5560 & 9.9241835181379651094E-2 & $\underline{4.1301811158584960765 \mathrm{E}+3}$ & $\underline{1.5015191380813064465 \mathrm{E}+3}$ & $\underline{0.39306264288077403467 \mathrm{E}+3}$ \\
\hline & 1005.308 & 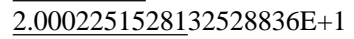 & $4.0679834708858382510 \mathrm{E}+3$ & $1.5349250109621962916 \mathrm{E}+3$ & $\overline{0.3874054009992} 1296375 \mathrm{E}+3$ \\
\hline & 1188.202 & 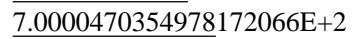 & $3.4613558020377671029 \mathrm{E}+3$ & 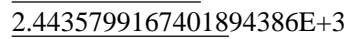 & $\overline{0.1326096164207} 5693598 \mathrm{E}+3$ \\
\hline \multirow[t]{4}{*}{500} & 0.435000 & $\overline{9.9967942317602} 231789 \mathrm{E}-2$ & $1.5081754139110436746 \mathrm{E}+3$ & $\overline{5.48314252654327} 71044 \mathrm{E}+2$ & $\overline{7.94488271364642} 13826 \mathrm{E}+3$ \\
\hline & 4.532000 & 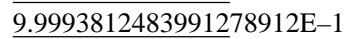 & $\overline{1.66991024524550} 69490 \mathrm{E}+3$ & $\overline{5.35739001345214} 77951 \mathrm{E}+2$ & $\overline{6.82502725276895} 84303 \mathrm{E}+3$ \\
\hline & 838.0250 & $1.0000385800922118506 \mathrm{E}+1$ & $3.2210621867405833518 \mathrm{E}+3$ & $1.2712844091476324779 \mathrm{E}+3$ & $2.5669091854222539144 \mathrm{E}+3$ \\
\hline & 1084.564 & 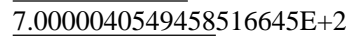 & $3.0743769300454436204 \mathrm{E}+3$ & $2.4120087657446758352 \mathrm{E}+3$ & $2.0323750919066389535 \mathrm{E}+3$ \\
\hline 647 & 358.0000 & $\overline{2.2038475570652} 149984 \mathrm{E}+1$ & $\overline{6.18315727666830} 92166 \mathrm{E}+3$ & $2.5214507827000715938 \mathrm{E}+2$ & $4.3209230667550033099 \mathrm{E}+3$ \\
\hline \multirow[t]{3}{*}{900} & 0.241000 & $\overline{1.000625586826} 6188154 \mathrm{E}-1$ & $1.7589065704448138520 \mathrm{E}+3$ & 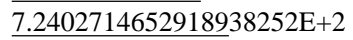 & $\overline{9.16653193855238} 42681 \mathrm{E}+3$ \\
\hline & 52.61500 & $\overline{2.00000690372146} 14551 \mathrm{E}+1$ & $\overline{1.93510525512622} 41493 \mathrm{E}+3$ & $\overline{6.98445673836795} 34276 \mathrm{E}+2$ & $\overline{6.59070224851012} 77853 \mathrm{E}+3$ \\
\hline & 870.7690 & $7.0000000575565402666 \mathrm{E}+2$ & $2.6642234977936996739 \mathrm{E}+3$ & $2.0193360824868338741 \mathrm{E}+3$ & $4.1722380158463258117 \mathrm{E}+3$ \\
\hline
\end{tabular}

of the PSS-78 salinity scale. Of couse, other limitations remain. For example, depending on the temperature, the supersaturation of high-salinity seawater may cause the precipitation of calcium minerals and thus a composition change of dissolved sea salt (Marion et al., 2008a, b). Composition anomalies due to this or other effects will degrade the accuracy of Reference-Composition Salinity as a measure of the Absolute Salinity used in the Gibbs function formulation of Feistel (2008). Such anomalies need to be taken into account to minimize inaccuracies.

The combination of the Helmholtz function for pure water, the Gibbs potential for salt-free ice and the saline part of the Gibbs potential for seawater provides a unified and fully consistent foundation for the consideration of the thermodynamic properties of pure water and seawater.

Mathematically, the combination of a Helmholtz function for the pure-water part with a Gibbs function for the saline part requires a proper use of theoretical thermodynamic methods and is not always a trivial exercise. For convenience of application, WG127 is implementing the new set of thermodynamic functions for liquid water, water vapor, ice, and seawater, as well as their mutual phase equilibria, in a comprehensive source code library for oceanographers and other scientists and engineers who deal with seawater (Feistel et al., 2009; Wright et al., 2009; McDougall et al., $2009 \mathrm{~b}$ ). In addition to the precise implementations of the relations discussed herein, efficient and accurate approximations for some quantities that require computationally efficient implementations will also be provided. Quantities such as entropy and enthalpy of seawater, which were not available from EOS-80, result naturally from the Gibbs function formalism, and the WG127 source code will include these quantities.

\section{Appendix A}

In this appendix the Tables A1-A8 with numerical check values published in the Releases IAPWS-95, IAPWS-06 and IAPWS- 08 are recomputed in quadruple precision. The original numerical check tables that IAPWS provides along with its Releases are intended to assist the user in verifying and debugging particular implementations of the formulation. For the easy detection of coding errors, these tables report 
Table A3. Quadruple-precision results for property values in the two-phase region at the selected values of temperature published in Table 8 of IAPWS-95 with the coefficients given in Table 1 of this paper ${ }^{\mathrm{a}}$. The underlined numbers indicate the digits that, based on our tests, can reasonably be expected to be reproduced using double-precision code.

\begin{tabular}{|c|c|c|c|c|}
\hline Property & $T=275 \mathrm{~K}$ & $T=450 \mathrm{~K}$ & $T=625 \mathrm{~K}$ & Unit \\
\hline$p^{\mathrm{W}}$ & $6.9845116670084935279 \mathrm{E}-4$ & $9.3220356362820145516 \mathrm{E}-1$ & $1.6908269318578409807 \mathrm{E}+1$ & $\mathrm{MPa}$ \\
\hline$p^{\text {Vap }}$ & 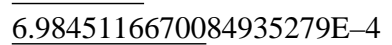 & 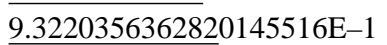 & 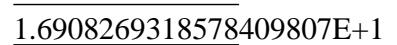 & $\mathrm{MPa}$ \\
\hline$\rho^{\mathrm{W}}$ & $\overline{9.9988740611984984069 \mathrm{E}+2}$ & 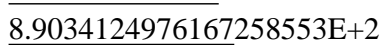 & $\overline{5.6709038514635254862 \mathrm{E}+2}$ & $\mathrm{~kg} \mathrm{~m}^{-3}$ \\
\hline$\rho^{\text {Vap }}$ & $5.5066491850412278079 \mathrm{E}-3$ & 4.8120036012567123262 & $1.1829028045115688596 \mathrm{E}+2$ & $\mathrm{~kg} \mathrm{~m}^{-3}$ \\
\hline$h^{\mathrm{W}}$ & 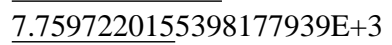 & $7.4916158501216908622 \mathrm{E}+5$ & $\overline{1.6862697594697419575 E+6}$ & $\mathrm{~J} \mathrm{~kg}^{-1}$ \\
\hline$h^{\text {Vap }}$ & $\overline{2.5042899500405145942 \mathrm{E}+6}$ & $\overline{2.7744107798896210429 \mathrm{E}+6}$ & $2.5507162456234704801 \mathrm{E}+6$ & $\mathrm{~J} \mathrm{~kg}^{-1}$ \\
\hline$s \mathrm{~W}$ & $2.8309466959519726149 \mathrm{E}+1$ & $2.1086584468844730194 \mathrm{E}+3$ & $3.8019468301114322634 \mathrm{E}+3$ & $\mathrm{~J} \mathrm{~kg}^{-1} \mathrm{~K}^{-1}$ \\
\hline$s^{\text {Vap }}$ & 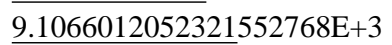 & 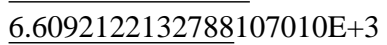 & $\overline{5.1850612079573} 978994 \mathrm{E}+3$ & $\mathrm{~J} \mathrm{~kg}^{-1} \mathrm{~K}^{-1}$ \\
\hline
\end{tabular}

${ }^{a}$ Each of these test values was calculated from the Helmholtz free energy by applying the phase-equilibrium condition (Maxwell criterion).

Table A4. Quadruple-precision results for the properties of pure ice at the triple point, the normal-pressure melting point and at $T=100 \mathrm{~K}$, $p=100 \mathrm{MPa}$. Results correspond to Table 6 of IAPWS-06 with the corrected coefficient $g_{00}$ of ice given in Table 1 . The underlined numbers indicate the digits that, based on our tests, can reasonably be expected to be reproduced using double-precision code.

\begin{tabular}{|c|c|c|c|c|}
\hline Property & $\begin{array}{l}\text { Value at } \\
T=T_{\mathrm{t}}=273.16 \mathrm{~K} \\
p=p_{\mathrm{t}}=611.657 \times 10^{-6} \mathrm{MPa}\end{array}$ & $\begin{array}{l}\text { Value at } \\
T=273.152519 \mathrm{~K} \\
p=0.101325 \mathrm{MPa}\end{array}$ & $\begin{array}{l}\text { Value at } \\
T=100 \mathrm{~K} \\
p=100 \mathrm{MPa}\end{array}$ & Unit \\
\hline$g$ & $6.1178413497053682445 \mathrm{E}-1$ & $1.0134274068780095492 \mathrm{E}+2$ & $-2.2229651308761583787 \mathrm{E}+5$ & $\mathrm{~J} \mathrm{~kg}^{-1}$ \\
\hline$(\partial g / \partial p)_{T}$ & 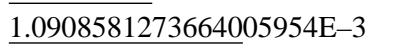 & 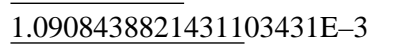 & $1.0619338925964914671 \mathrm{E}-3$ & $\mathrm{~m}^{3} \mathrm{~kg}^{-1}$ \\
\hline$(\partial g / \partial T)_{p}$ & $1.2206943393968694463 \mathrm{E}+3$ & $1.2207693254969558410 \mathrm{E}+3$ & $2.6119512258878494194 \mathrm{E}+3$ & $\mathrm{~J} \mathrm{~kg}^{-1} \mathrm{~K}^{-1}$ \\
\hline$\left(\partial^{2} g / \partial p^{2}\right)_{T}$ & $-1.2849594157149444477 \mathrm{E}-13$ & $-1.2848536492845547078 \mathrm{E}-13$ & $-9.4180798176091398970 \mathrm{E}-14$ & $\mathrm{~m}^{3} \mathrm{~kg}^{-1} \mathrm{~Pa}^{-1}$ \\
\hline$\partial^{2} g / \partial p \partial T$ & $1.7438796469959804034 \mathrm{E}-7$ & $1.7436221997215907057 \mathrm{E}-7$ & $2.7450516248810767755 \mathrm{E}-8$ & $\mathrm{~m}^{3} \mathrm{~kg}^{-1} \mathrm{~K}^{-1}$ \\
\hline$\left(\partial^{2} g / \partial T^{2}\right)_{p}$ & -7.6760298587506742565 & -7.6759823336479766851 & $-\underline{8.6633319551683378537}$ & $\mathrm{~J} \mathrm{~kg}^{-1} \mathrm{~K}^{-2}$ \\
\hline$h$ & $-\overline{3.33444253965513} 88743 \mathrm{E}+5$ & $-\overline{3.33354873636736} 61384 \mathrm{E}+5$ & $-\overline{4.83491635676400} 77981 \mathrm{E}+5$ & $\mathrm{~J} \mathrm{~kg}^{-1}$ \\
\hline$f$ & 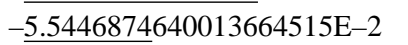 & $-\overline{9.1870156703497005930}$ & $-\overline{3.2848990234726498458 \mathrm{E}+5}$ & $\mathrm{~J} \mathrm{~kg}^{-1}$ \\
\hline$u$ & $-\overline{3.3344492119652349798 \mathrm{E}+5}$ & $-3.3346540339309476449 \mathrm{E}+5$ & $-\overline{5.8968502493604992651 \mathrm{E}+5}$ & $\mathrm{~J} \mathrm{~kg}^{-1}$ \\
\hline$s$ & $-1.2206943393968694463 \mathrm{E}+3$ & $-\overline{1.22076932549695} 58410 \mathrm{E}+3$ & $-2.6119512258878494194 \mathrm{E}+3$ & $\mathrm{~J} \mathrm{~kg}^{-1} \mathrm{~K}^{-1}$ \\
\hline$c_{p}$ & $2.0967843162163341799 \mathrm{E}+3$ & $2.0967139102354432908 \mathrm{E}+3$ & $8.6633319551683378537 \mathrm{E}+2$ & $\mathrm{~J} \mathrm{~kg}^{-1} \mathrm{~K}^{-1}$ \\
\hline$\rho$ & $9.1670949219972864196 \mathrm{E}+2$ & $9.1672146341909600300 \mathrm{E}+2$ & $9.4167820329657299139 \mathrm{E}+2$ & $\mathrm{~kg} \mathrm{~m}^{-3}$ \\
\hline$\alpha$ & $1.5986310256551272353 \mathrm{E}-4$ & $1.5984158945787999191 \mathrm{E}-4$ & $2.5849552820743506386 \mathrm{E}-5$ & $\mathrm{~K}^{-1}$ \\
\hline$\beta$ & $1.3571476465859392367 \mathrm{E}+6$ & $1.3570589932110105876 \mathrm{E}+6$ & $2.9146616699389277480 \mathrm{E}+5$ & $\mathrm{~Pa} \mathrm{~K}^{-1}$ \\
\hline$\kappa_{T}$ & 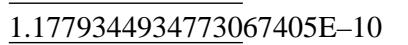 & 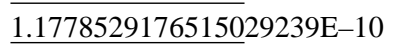 & 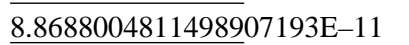 & $\mathrm{Pa}^{-1}$ \\
\hline$\kappa_{s}$ & 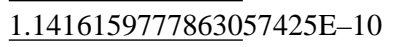 & $\overline{1.14154442556498} 04160 \mathrm{E}-10$ & $\overline{8.86060982686811} 64748 \mathrm{E}-11$ & $\mathrm{~Pa}^{-1}$ \\
\hline
\end{tabular}

numbers with more digits than required by the experimental accuracy. They report fewer digits than available from a typical 64-bit floating point number and suppress the part which very likely varies between different implementations, since those digits may be more confusing than helpful for the examination of the code's correctness. Thus, with respect to these published check values, all correct and well-organised implementations are considered equally good.

For certain applications of the Releases, as e.g. for the development of a source code library for seawater, it is important to estimate the implementation errors, i.e., the deviations from the mathematical formulations. This is of interest when speed-optimized code is required for circulation models or other time-critical applications, to monitor the degree to which the precision of the results is diminished by certain accelerating modifications or simplifications. This is also of interest to see the effects of reorganising internal details of the code, the sequence of execution, the grouping into procedures, etc.

For these reasons, we are publishing alternative versions of the IAPWS tables with numerical check values for fluid water, ice and seawater with very high accuracy, typically 20 or more valid digits. 
Table A5. Quadruple-precision results for the water part, saline part and total properties published in Table 8a of IAPWS-08 with the coefficients given in Table 1 of this paper. Properties at $S_{\mathrm{A}}=S_{\mathrm{n}}=0.03516504 \mathrm{~kg} \mathrm{~kg}^{-1}, T=T_{0}=273.15 \mathrm{~K}, p=p_{0}=0.101325 \mathrm{MPa}$. The underlined numbers indicate the digits that, based on our tests, can reasonably be expected to be reproduced using double-precision code.

\begin{tabular}{|c|c|c|c|c|}
\hline Property & Water part & Saline part & Property of seawater & Unit \\
\hline$g$ & $1.0134274172939062882 \mathrm{E}+2$ & $-1.0134274172939062882 \mathrm{E}+2$ & $-2 . \mathrm{E}-29^{\mathrm{b}}, 4 . \mathrm{E}-9^{\mathrm{b}}$ & $\mathrm{J} \mathrm{kg}^{-1}$ \\
\hline$\left(\partial g / \partial S_{\mathrm{A}}\right)_{T, p}$ & $\overline{\underline{0.0}}$ & $\underline{6.39974067312299} 04527 \mathrm{E}+4$ & 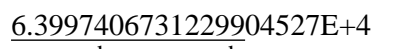 & $\mathrm{J} \mathrm{kg}^{-1}$ \\
\hline$(\partial g / \partial T)_{S, p}$ & 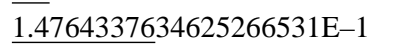 & $-1.4764337634625266531 \mathrm{E}-1$ & $\overline{7 . E-32^{b},-6 . E-11^{b}}$ & $\mathrm{~J} \mathrm{~kg}^{-1} \mathrm{~K}^{-1}$ \\
\hline$(\partial g / \partial p)_{S, T}$ & $1.0001569391216926347 \mathrm{E}-3$ & $-2.7495722426843287457 \mathrm{E}-5$ & $9.7266121669484934729 \mathrm{E}-4$ & $\mathrm{~m}^{3} \mathrm{~kg}^{-1}$ \\
\hline$\left(\partial^{2} g / \partial S_{\mathrm{A}} \partial p\right)_{T}$ & $\overline{0.0}$ & 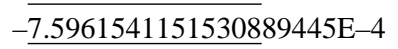 & 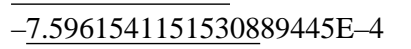 & $\mathrm{m}^{3} \mathrm{~kg}^{-1}$ \\
\hline$\left(\partial^{2} g / \partial T^{2}\right)_{S, p}$ & $-1.5447354231977289339 \mathrm{E}+1$ & $8.5286115117592251026 \mathrm{E}-1$ & $-1.4594493080801366829 \mathrm{E}+1$ & $\mathrm{~J} \mathrm{~kg}^{-1} \mathrm{~K}^{-2}$ \\
\hline$\left(\partial^{2} g / \partial T \partial p\right)_{S}$ & 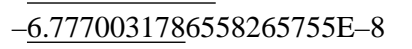 & $\overline{1.1928678741395} 764132 \mathrm{E}-7$ & 5.1516755627399375563E-8 & $\mathrm{m}^{3} \mathrm{~kg}^{-1} \mathrm{~K}^{-1}$ \\
\hline$\left(\partial^{2} g / \partial p^{2}\right)_{S, T}$ & $-\overline{-5.08928894643} 49017238 \mathrm{E}-13$ & $\overline{5.8153517233288} 224927 \mathrm{E}-14$ & $-4.5077537741020194745 \mathrm{E}-13$ & $\mathrm{~m}^{3} \mathrm{~kg}^{-1} \mathrm{~Pa}^{-1}$ \\
\hline$h$ & $6.1013953480411713295 \mathrm{E}+1$ & $-6.1013953480411713295 \mathrm{E}+1$ & $-4 . \mathrm{E}-29^{\mathrm{b}}, 2 . \mathrm{E}-8^{\mathrm{b}}$ & $\mathrm{J} \mathrm{kg}^{-1}$ \\
\hline$f$ & 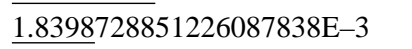 & 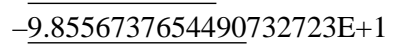 & 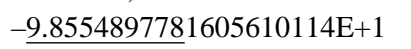 & $\mathrm{J} \mathrm{kg}^{-1}$ \\
\hline$u$ & $-4.0326948376093792920 \mathrm{E}+1$ & $-5.8227949405511817194 \mathrm{E}+1$ & $-9.8554897781605610114 \mathrm{E}+1$ & $\mathrm{~J} \mathrm{~kg}^{-1}$ \\
\hline$s$ & $-\overline{-1.47643376} 34625266530 \mathrm{E}-1$ & $1 \overline{.476433763462} 5266531 \mathrm{E}-1$ & $-7 . \mathrm{E}-32^{\mathrm{b}}, 6 . \mathrm{E}-11^{\mathrm{b}}$ & $\mathrm{J} \mathrm{kg}^{-1} \mathrm{~K}^{-1}$ \\
\hline$\rho$ & 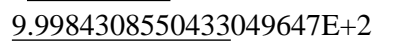 & $\overline{-^{a}}$ & $1.0281071999540078127 \mathrm{E}+3$ & $\mathrm{~kg} \mathrm{~m}^{-3}$ \\
\hline$c_{p}$ & $\overline{4.2194448084645} 965831 \mathrm{E}+3$ & $-2.3295902344370323368 \mathrm{E}+2$ & $3.9864857850208933494 \mathrm{E}+3$ & $\mathrm{~J} \mathrm{~kg}^{-1} \mathrm{~K}^{-1}$ \\
\hline$w$ & $1.4023825310882262606 \mathrm{E}+3$ & $-\mathrm{a}$ & $1.4490024636214836206 \mathrm{E}+3$ & $\mathrm{~m} \mathrm{~s}^{-1}$ \\
\hline$\mu_{\mathrm{W}}$ & $1.0134274172939062882 \mathrm{E}+2$ & 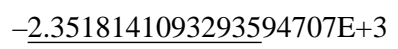 & $-2.2504713675999688419 \mathrm{E}+3$ & $\mathrm{~J} \mathrm{~kg}^{-1}$ \\
\hline
\end{tabular}

a The quantities $\rho$ and $w$ are nonlinear in $g$ and hence cannot be computed from $g^{\mathrm{S}}$ alone.

$\mathrm{b}$ Each of these numbers is identically zero in the theoretical model. The numbers shown here give the roundoff errors corresponding to quadruple- and double-precision implementations, respectively.

Table A6. Quadruple-precision results for the water part, saline part and total properties published in Table $8 \mathrm{~b}$ of IAPWS- 08 with the coefficients given in Table 1 of this paper. Properties at $S_{\mathrm{A}}=0.1 \mathrm{~kg} \mathrm{~kg}^{-1}=100 \mathrm{~g} \mathrm{~kg}^{-1}, T=353 \mathrm{~K}, p=p_{0}=0.101325 \mathrm{MPa}$. This point is located in the regions with restricted validity. The underlined numbers indicate the digits that, based on our tests, can reasonably be expected to be reproduced using double-precision code.

\begin{tabular}{|c|c|c|c|c|}
\hline Property & Water part & Saline part & Property of seawater & Unit \\
\hline$g$ & 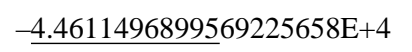 & $1.5087174003705274197 \mathrm{E}+4$ & $-2.9524322895863951462 \mathrm{E}+4$ & $\mathrm{~J} \mathrm{~kg}^{-1}$ \\
\hline$\left(\partial g / \partial S_{\mathrm{A}}\right)_{T, p}$ & 0.0 & $2.5195727585141284916 \mathrm{E}+5$ & $2 . \overline{519572758514} 1284916 \mathrm{E}+5$ & $\mathrm{~J} \mathrm{~kg}^{-1}$ \\
\hline$(\partial g / \partial T)_{S, p}$ & $-1.0737599318874549194 \mathrm{E}+3$ & $1.5623090740429099119 \mathrm{E}+2$ & $-9.1752902448316392819 \mathrm{E}+2$ & $\mathrm{~J} \mathrm{~kg}^{-1} \mathrm{~K}^{-1}$ \\
\hline$(\partial g / \partial p)_{S, T}$ & $1.0289295563561100700 \mathrm{E}-3$ & $\overline{-5.7922728577125} 827635 \mathrm{E}-5$ & $9 \overline{7100682777898} 424241 \mathrm{E}-4$ & $\mathrm{~m}^{3} \mathrm{~kg}^{-1}$ \\
\hline$\left(\partial^{2} g / \partial S_{\mathrm{A}} \partial p\right)_{T}$ & 0.0 & $-3.0595780244233918005 \mathrm{E}-4$ & $-3.0595780244233918005 \mathrm{E}-4$ & $\mathrm{~m}^{3} \mathrm{~kg}^{-1}$ \\
\hline$\left(\partial^{2} g / \partial T^{2}\right)_{S, p}$ & $-1.1888500004754679683 \mathrm{E}+1$ & $1.2792264931550738238 \mathrm{E}+0$ & $-1.0609273511599605860 \mathrm{E}+1$ & $\mathrm{~J} \mathrm{~kg}^{-1} \mathrm{~K}^{-2}$ \\
\hline$\left(\partial^{2} g / \partial T \partial p\right)_{S}$ & $6.5905155233936161134 \mathrm{E}-7$ & $8.0306159575153091195 \mathrm{E}-7$ & $1.4621131480908925233 \mathrm{E}-6$ & $\mathrm{~m}^{3} \mathrm{~kg}^{-1} \mathrm{~K}^{-1}$ \\
\hline$\left(\partial^{2} g / \partial p^{2}\right)_{S, T}$ & $-4.7467281936106728585 \mathrm{E}-13$ & $2.1308615424374026844 \mathrm{E}-13$ & $-2.6158666511732701741 \mathrm{E}-13$ & $\mathrm{~m}^{3} \mathrm{~kg}^{-1} \mathrm{~Pa}^{-1}$ \\
\hline$h$ & $3 . \overline{3442575905670236088 \mathrm{E}+5}$ & $-4.0062336310009445692 \mathrm{E}+4$ & $2.943634227466929152 \mathrm{E}+5$ & $\mathrm{~J} \mathrm{~kg}^{-1}$ \\
\hline$f$ & $-4.4715753186867008511 \mathrm{E}+4$ & $1.5093043024178351471 \mathrm{E}+4$ & $-2.962271016268865704 \mathrm{E}+4$ & $\mathrm{~J} \mathrm{~kg}^{-1}$ \\
\hline$u$ & $3 . \overline{343215027694} 0457803 \mathrm{E}+5$ & $-4.0056467289536368418 \mathrm{E}+4$ & $2.9426503547986820961 \mathrm{E}+5$ & $\mathrm{~J} \mathrm{~kg}^{-1}$ \\
\hline$s$ & $1.0737599318874549194 \mathrm{E}+3$ & $-\overline{1.5623090740429} 099119 \mathrm{E}+2$ & $\overline{9.1752902448316392819 \mathrm{E}+2}$ & $\mathrm{~J} \mathrm{~kg}^{-1} \mathrm{~K}^{-1}$ \\
\hline$\rho$ & $9.7188383191307839206 \mathrm{E}+2$ & $a$ & $1.0298588757479005489 \mathrm{E}+3$ & $\mathrm{~kg} \mathrm{~m}^{-3}$ \\
\hline$c_{p}$ & 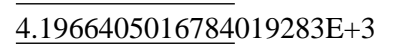 & $-4.5156695208374105981 \mathrm{E}+2$ & $\overline{3.7450735495946608685 \mathrm{E}+3}$ & $\mathrm{~J} \mathrm{~kg}^{-1} \mathrm{~K}^{-1}$ \\
\hline$w$ & $1.5544629665347162190 \mathrm{E}+3$ & $\_\mathrm{a}$ & $3.9612783529250024954 \mathrm{E}+3$ & $\mathrm{~m} \mathrm{~s}^{-1}$ \\
\hline$\mu_{\mathrm{W}}$ & $-4.4611496899569225658 \mathrm{E}+4$ & $-1.0108553581436010719 \mathrm{E}+4$ & $-5.4720050481005236377 \mathrm{E}+4$ & $\mathrm{~J} \mathrm{~kg}^{-1}$ \\
\hline
\end{tabular}

a The quantities $\rho$ and $w$ are nonlinear in $g$ and hence cannot be computed from $g^{S}$ alone. 
Table A7. Quadruple-precision results for the water part, saline part and total properties published in Table $8 \mathrm{c}$ of IAPWS-08 with the coefficients given in Table 1 of this paper. Properties at $S_{\mathrm{A}}=0.03516504 \mathrm{~kg} \mathrm{~kg}^{-1}, T=T_{0}=273.15 \mathrm{~K}, p=100 \mathrm{MPa}$. The underlined numbers indicate the digits that, based on our tests, can reasonably be expected to be reproduced using double-precision code.

\begin{tabular}{|c|c|c|c|c|}
\hline Property & Water part & Saline part & Property of seawater & Unit \\
\hline$g$ & $9.7730386219537338734 \mathrm{E}+4$ & $-2.6009305073063660852 E+3$ & $9.5129455712230972649 \mathrm{E}+4$ & $\mathrm{~J} \mathrm{~kg}^{-1}$ \\
\hline$\left(\partial g / \partial S_{\mathrm{A}}\right)_{T, p}$ & 0.0 & $-5.4586158064879659787 \mathrm{E}+3$ & $-5.4586158064879659787 \mathrm{E}+3$ & $\mathrm{~J} \mathrm{~kg}^{-1}$ \\
\hline$(\partial g / \partial T)_{S, p}$ & 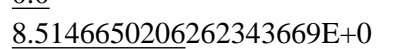 & $7.5404568488116539426 \mathrm{E}+0$ & $1.6055121869437888309 \mathrm{E}+1$ & $\mathrm{~J} \mathrm{~kg}^{-1} \mathrm{~K}^{-1}$ \\
\hline$(\partial g / \partial p)_{S, T}$ & $9.5668332915350911569 \mathrm{E}-4$ & $-2.2912384179113101721 \mathrm{E}-5$ & $9.3377094497439601397 \mathrm{E}-4$ & $\mathrm{~m}^{3} \mathrm{~kg}^{-1}$ \\
\hline$\left(\partial^{2} g / \partial S_{\mathrm{A}} \partial p\right)_{T}$ & 0.0 & $-6.4075761854574757172 \mathrm{E}-4$ & $-6.4075761854574757172 \mathrm{E}-4$ & $\mathrm{~m}^{3} \mathrm{~kg}^{-1}$ \\
\hline$\left(\partial^{2} g / \partial T^{2}\right)_{S, p}$ & 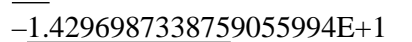 & $4.8807697394225122581 \mathrm{E}-1$ & 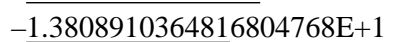 & $\mathrm{J} \mathrm{kg}^{-1} \mathrm{~K}^{-2}$ \\
\hline$\left(\partial^{2} g / \partial T \partial p\right)_{S}$ & $1.9907957080315389517 \mathrm{E}-7$ & $4.6628441224121312517 \mathrm{E}-8$ & $2.4570801202727520769 \mathrm{E}-7$ & $\mathrm{~m}^{3} \mathrm{~kg}^{-1} \mathrm{~K}^{-1}$ \\
\hline$\left(\partial^{2} g / \partial p^{2}\right)_{S, T}$ & $-3.7153088942341756981 \mathrm{E}-13$ & $3.5734573584532666554 \mathrm{E}-14$ & $-3.3579631583888490325 \mathrm{E}-13$ & $\mathrm{~m}^{3} \mathrm{~kg}^{-1} \mathrm{~Pa}^{-1}$ \\
\hline$h$ & $9.5404605469153282817 \mathrm{E}+4$ & $-4.6606062955592693597 \mathrm{E}+3$ & $9.0743999173594013457 \mathrm{E}+4$ & $\mathrm{~J} \mathrm{~kg}^{-1}$ \\
\hline$f$ & $2.0620533041864271652 \mathrm{E}+3$ & $-3.0969208939505591314 \mathrm{E}+2$ & $1.7523612147913712521 \mathrm{E}+3$ & $\mathrm{~J} \mathrm{~kg}^{-1}$ \\
\hline$u$ & $-2.6372744619762875211 \mathrm{E}+2$ & $-\overline{-2.3693678776479591876 \mathrm{E}+3}$ & $-2.6330953238455879397 \mathrm{E}+3$ & $\mathrm{~J} \mathrm{~kg}^{-1}$ \\
\hline$s$ & $-8.5146650206262343669 \mathrm{E}+0$ & $-7.5404568488116539426 \mathrm{E}+0$ & $-1.6055121869437888309 \mathrm{E}+1$ & $\mathrm{~J} \mathrm{~kg}^{-1} \mathrm{~K}^{-1}$ \\
\hline$\rho$ & $1.0452779613969214514 \mathrm{E}+3$ & $-\mathrm{a}$ & $1.0709264465574263352 \mathrm{E}+3$ & $\mathrm{~kg} \mathrm{~m}^{-3}$ \\
\hline$c_{p}$ & $3.9052220915820361447 \mathrm{E}+3$ & $-1.3331822543232592233 \mathrm{E}+2$ & $3.7719038661497102223 \mathrm{E}+3$ & $\mathrm{~J} \mathrm{~kg}^{-1} \mathrm{~K}^{-1}$ \\
\hline$w$ & $1.5754223984859303496 \mathrm{E}+3$ & $-^{\mathrm{a}}$ & $1.6219899764987563752 \mathrm{E}+3$ & $\mathrm{~m} \mathrm{~s}^{-1}$ \\
\hline$\mu_{\mathrm{W}}$ & $9.7730386219537338734 \mathrm{E}+4$ & $-2.4089780641265845021 \mathrm{E}+3$ & $9.5321408155410754232 \mathrm{E}+4$ & $\mathrm{~J} \mathrm{~kg}^{-1}$ \\
\hline
\end{tabular}

a The quantities $\rho$ and $w$ are nonlinear in $g$ and hence cannot be computed from $g \mathrm{~S}$ alone.

Table A8. Quadruple-precision results for the properties of water, ice and seawater at the standard ocean state, computed with all coefficients as given in Table 1 of this paper. $T=273.15 \mathrm{~K}, p=0.101325 \mathrm{MPa}$ and $S_{\mathrm{A}}=0.03516504$ for seawater. The underlined numbers indicate the digits that, based on our tests, can reasonably be expected to be reproduced using double-precision code.

\begin{tabular}{|c|c|c|c|c|}
\hline Property & Property of water & Property of ice & Property of seawater & Unit \\
\hline$g$ & 1.0134274172939062882E+2 & $9.8267598403431717064 \mathrm{E}+1$ & $-2 . \mathrm{E}-29^{\mathrm{a}}, 4 . \mathrm{E}-9^{\mathrm{a}}$ & $\mathrm{J} \mathrm{kg}^{-1}$ \\
\hline$\left(\partial g / \partial S_{\mathrm{A}}\right)_{T, p}$ & $\overline{\underline{0.0}}$ & $\overline{0.0}$ & 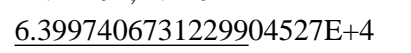 & $\mathrm{J} \mathrm{kg}^{-1}$ \\
\hline$(\partial g / \partial T)_{S, p}$ & $1.4764337634625266531 \mathrm{E}-1$ & $1.2207886612999530642 \mathrm{E}+3$ & 7.E $-32^{\mathrm{a}},-6 . \mathrm{E}-11^{\mathrm{a}}$ & $\mathrm{J} \mathrm{kg}^{-1} \mathrm{~K}^{-1}$ \\
\hline$(\partial g / \partial p)_{S, T}$ & 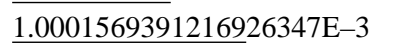 & $\overline{1.09084344292643} 52467 \mathrm{E}-3$ & $\underline{9.7266121669484934729 \mathrm{E}-4}$ & $\mathrm{~m}^{3} \mathrm{~kg}^{-1}$ \\
\hline$\left(\partial^{2} g / \partial S_{\mathrm{A}} \partial p\right)_{T}$ & $\overline{0.0}$ & $\overline{0.0}$ & $-7.5961541151530889445 \mathrm{E}-4$ & $\mathrm{~m}^{3} \mathrm{~kg}^{-1}$ \\
\hline$\left(\partial^{2} g / \partial T^{2}\right)_{S, p}$ & 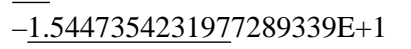 & $\overline{-7.6759851115667509185 \mathrm{E}+0}$ & $-1.4594493080801366829 \mathrm{E}+1$ & $\mathrm{~J} \mathrm{~kg}^{-1} \mathrm{~K}^{-2}$ \\
\hline$\left(\partial^{2} g / \partial T \partial p\right)_{S}$ & $-6.7770031786558265755 \mathrm{E}-8$ & $1.7436082496084962410 \mathrm{E}-7$ & $5.1516755627399375563 \mathrm{E}-8$ & $\mathrm{~m}^{3} \mathrm{~kg}^{-1} \mathrm{~K}^{-1}$ \\
\hline$\left(\partial^{2} g / \partial p^{2}\right)_{S, T}$ & $-\overline{-5.0892889464349017238 \mathrm{E}-13}$ & $-1.2848482463976179327 \mathrm{E}-13$ & 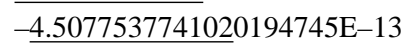 & $\mathrm{m}^{3} \mathrm{~kg}^{-1} \mathrm{~Pa}^{-1}$ \\
\hline$h$ & 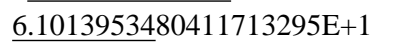 & $-3.3336015523567874778 \mathrm{E}+5$ & $-4 . \mathrm{E}-29^{\mathrm{a}}, 2 . \mathrm{E}-8^{\mathrm{a}}$ & $\mathrm{J} \mathrm{kg}^{-1}$ \\
\hline$f$ & $1.8398728851226087838 \mathrm{E}-3$ & $-1.2262113451089334305 \mathrm{E}+1$ & $-9.8554897781605610114 \mathrm{E}+1$ & $\mathrm{~J} \mathrm{~kg}^{-1}$ \\
\hline$u$ & $-4.0326948376093792920 \mathrm{E}+1$ & $-3.3347068494753326883 \mathrm{E}+5$ & $-9.8554897781605610114 \mathrm{E}+1$ & $\mathrm{~J} \mathrm{~kg}^{-1}$ \\
\hline$s$ & $-1.4764337634625266531 \mathrm{E}-1$ & $-1.2207886612999530642 \mathrm{E}+3$ & 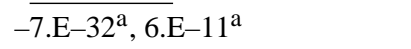 & $\mathrm{J} \mathrm{kg}^{-1} \mathrm{~K}^{-1}$ \\
\hline$\rho$ & 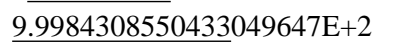 & $9.1672183252738167257 \mathrm{E}+2$ & $1.0281071999540078127 \mathrm{E}+3$ & $\mathrm{~kg} \mathrm{~m}^{-3}$ \\
\hline$c_{p}$ & $4.2194448084645965831 \mathrm{E}+3$ & $2.0966953332244580134 \mathrm{E}+3$ & $3.9864857850208933494 \mathrm{E}+3$ & $\mathrm{~J} \mathrm{~kg}^{-1} \mathrm{~K}^{-1}$ \\
\hline$\alpha$ & $-6.7759397686198971741 \mathrm{E}-5$ & $\overline{1.59840374979096} 09918 \mathrm{E}-4$ & $5.2964747378800447017 \mathrm{E}-5$ & $\mathrm{~K}^{-1}$ \\
\hline$\kappa_{T}$ & $5.0884903632265555122 \mathrm{E}-10$ & $1.1778484389572171289 \mathrm{E}-10$ & 4.6344541107741383004E-10 & $\mathrm{Pa}^{-1}$ \\
\hline$\kappa_{S}$ & $\overline{5.0855176492808069170 \mathrm{E}-10}$ & $1.1415405263722770087 \mathrm{E}-10$ & 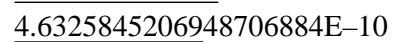 & $\mathrm{Pa}^{-1}$ \\
\hline$\mu_{\mathrm{W}}$ & $1.0134274172939062882 \mathrm{E}+2$ & $\overline{9.82675984034317} 17064 \mathrm{E}+1$ & $-2.2504713675999688419 \mathrm{E}+3$ & $\mathrm{~J} \mathrm{~kg}^{-1}$ \\
\hline
\end{tabular}

${ }^{a}$ Each of these numbers is identically zero in the theoretical model. The numbers shown here give the roundoff errors corresponding to quadruple- and double-precision implementations, respectively. 
Table A9. Formulas for properties reported in Tables A2-A8, expressed in terms of partial derivatives of the Helmholtz function $f(T, \rho)$ of fluid water and the Gibbs functions $g(T, p)$ of ice and $g\left(S_{\mathrm{A}}, T, p\right)$ of seawater.

\begin{tabular}{|c|c|c|c|c|}
\hline Property & $\begin{array}{l}\text { Expression in } \\
g(S, T, p) \text { of seawater }\end{array}$ & $\begin{array}{l}\text { Expression in } \\
g(T, p) \text { of ice }\end{array}$ & $\begin{array}{l}\text { Expression in } \\
f(T, \rho) \text { of fluid water }\end{array}$ & Comment \\
\hline $\begin{array}{l}g \\
\left(\partial g / \partial S_{\mathrm{A}}\right)_{T, p}\end{array}$ & $\begin{array}{l}g \\
g_{S}\end{array}$ & $\begin{array}{l}g \\
0\end{array}$ & $\begin{array}{l}f+\rho f_{\rho} \\
0\end{array}$ & specific Gibbs energy \\
\hline$(\partial g / \partial T)_{S, p}$ & $g_{T}$ & $g_{T}$ & $f_{T}$ & \\
\hline$(\partial g / \partial p)_{S, T}$ & $g_{p}$ & $g_{p}$ & $\rho^{-1}$ & \\
\hline$\left(\partial^{2} g / \partial S_{\mathrm{A}} \partial p\right)_{T}$ & $g_{S p}$ & 0 & 0 & \\
\hline$\left(\partial^{2} g / \partial T^{2}\right)_{S, p}$ & $g_{T T}$ & $g_{T T}$ & $f_{T T}-\rho f_{\rho T}^{2} /\left(2 f_{\rho}+\rho f_{\rho \rho}\right)$ & \\
\hline$\left(\partial^{2} g / \partial T \partial p\right)_{S}$ & $g_{T p}$ & $g_{T p}$ & $f_{\rho T} /\left(2 \rho f_{\rho}+\rho^{2} f_{\rho \rho}\right)$ & \\
\hline$\left(\partial^{2} g / \partial p^{2}\right)_{S, T}$ & $g_{p p}$ & $g_{p p}$ & $-1 /\left\{\rho^{3}\left(2 f_{\rho}+\rho f_{\rho \rho}\right)\right\}$ & \\
\hline$h$ & $g-T g_{T}$ & $g-T g_{T}$ & $f-T f_{T}+\rho f_{\rho}$ & specific enthalpy \\
\hline$f$ & $g-p g_{p}$ & $g-p g_{p}$ & $f$ & specific Helmholtz energy \\
\hline$u$ & $g-T g_{T}-p g_{p}$ & $g-T g_{T}-p g_{p}$ & $f-T f_{T}$ & specific internal energy \\
\hline$s$ & $-g_{T}$ & $-g_{T}$ & $-f_{T}$ & specific entropy \\
\hline$p$ & $p$ & $p$ & $\rho^{2} f_{\rho}$ & pressure \\
\hline$\rho$ & $1 / g_{p}$ & $1 / g_{p}$ & $\rho$ & density \\
\hline$c_{p}$ & $-T g_{T T}$ & $-T g_{T T}$ & $T\left\{\rho f_{T \rho}^{2}\left(2 f_{\rho}+\rho f_{\rho \rho}\right)-f_{T T}\right\}$ & specific isobaric heat capacity \\
\hline$\alpha$ & $g_{T p} / g_{p}$ & $g_{T p} / g_{p}$ & $f_{T \rho} /\left(2 f_{\rho}+\rho f_{\rho \rho}\right)$ & thermal expansion \\
\hline$\kappa_{T}$ & $-g_{p p} / g_{p}$ & $-g_{p p} / g_{p}$ & $1 /\left\{\rho^{2}\left(2 f_{\rho}+\rho f_{\rho \rho}\right)\right\}$ & isothermal compressibility \\
\hline$\kappa_{s}$ & $\left(g_{T p}^{2}-g_{T T} g_{p p}\right) /\left(g_{p} g_{T T}\right)$ & $\left(g_{T p}^{2}-g_{T T} g_{p p}\right) /\left(g_{p} g_{T T}\right)$ & $f_{T T} /\left\{\rho^{2} f_{T T}\left(2 f_{\rho}+\rho f_{\rho \rho}\right)-\rho^{3} f_{T \rho}^{2}\right\}$ & isentropic compressibility \\
\hline$w$ & $g_{p} \sqrt{g_{T T} /\left(g_{T p}^{2}-g_{T T} g_{p p}\right)}$ & $-^{\mathrm{a}}$ & $\sqrt{\rho^{2}\left(f_{T T} f_{\rho \rho}-f_{\rho T}^{2}\right) / f_{T T}+2 \rho f_{\rho}}$ & sound speed \\
\hline$\mu_{\mathrm{W}}$ & $g-S_{\mathrm{A}} g_{S}$ & $g$ & $f+\rho f_{\rho}$ & chemical potential of water \\
\hline$\beta$ & - & $-g_{T p} / g_{p p}$ & - & pressure coefficient for ice \\
\hline
\end{tabular}

a Sound speeds in solid crystals cannot be computed from volume compressibility.

In addition to these tables with numerical check values, we report in this appendix properties of liquid water, water vapor, ice and seawater at the reference states explained in Sect. 3.

Underlining in all tables shows the digits of the more accurate quadruple-precision results that typical double-precision implementations of the fluid, ice and seawater potential functions should be able to reproduce. This underlining was determined using two independent techniques. The first method is based on a manual comparison of double- and quadrupleprecision results and the observation that different implementations of the potential functions in double-precision arithmetic give the same agreement with the quadruple-precision table entries to within one digit. We compared two different implementations in two different languages on different machines and operating systems. Both implementations used the values of the arbitrary adjustable constants as listed in Table 1 but rounded to 15 decimal digits, as is consistent with double-precision code.
The second technique is based on calculating the relative condition numbers (Dahlquist et al., 2008) of the evaluations of the table entries. These condition numbers measure the sensitivities of the computations to small perturbations of input variables and the number of digits lost in the computation of a given quantity is given by the logarithm to the base 10 of the corresponding relative condition number. In all but a few of the comparisons between the two accuracy estimates, the estimate from condition number is smaller, in terms of number of digits of accuracy, than the agreement between the double- and quadruple-precision results. The differences between estimates arise primarily because condition number is real and requires rounding or truncating to give its integer estimate. Also, the precision of computations on a given platform may be slightly better than 15 significant figures. The underlined digits in the tables are intended to be on the conservative side in that they show the minimum number of digits expected to be correctly reproduced by double-precision code based on our three estimates (the two double-precision estimates and the condition number estimate). Code that 
reproduces the quadruple-precision results to one fewer digit is probably still within the range of uncertainty but two fewer digits of agreement would be cause for concern about the integrity of the code.

Formulas for the computation of thermodynamic properties from the potentials $f$ and $g$ are summarized in Table A9.

Acknowledgements. This paper was presented at the 15th International Conference on the Properties of Water and Steam, September 2008 , in Berlin, Germany. It is partially a contribution of the National Institute of Standards and Technology and is not subject to copyright in the US.

This work contributes to the tasks of the SCOR/IAPSO Working Group 127 on the Thermodynamics and Equation of State of Seawater.

Edited by: R. Tailleux

\section{References}

Asada, S., Sotani, T., Arabas, J., Kubota, H., Matsuo S., and Tanaka, Y.: Density of water at subzero temperature under high pressure: measurements and correlation, J. Phys.: Condens. Matter, 14, 11447-11452, 2002.

Bailey, D. H., Hida, Y., Jeyabalan, K., Li, X. S., and Thompson, B.: High-precision software directory, available at: http://crd.lbl. gov/ dhbailey/mpdist/, 2008.

BIPM: The International System of Units (SI), Organisation Intergouvernementale de la Convention du Mètre, Paris, available at: http://www.bipm.fr/utils/common/pdf/si_brochure_8_en.pdf, 2006.

Dahlquist, A., Björck, A., and Anderson, N.: Numerical Methods, Prentice-Hall Series in Automatic Computation, 573 pp., 1974.

Feistel, R.: Equilibrium thermodynamics of seawater revisited, Progr. Oceanogr., 31, 101-179, 1993.

Feistel, R.: A new extended Gibbs thermodynamic potential of seawater, Progr. Oceanogr., 58, 43-114, 2003.

Feistel, R.: Numerical implementation and oceanographic application of the Gibbs thermodynamic potential of seawater, Ocean Sci., 1, 9-16, available at: http://www.ocean-sci.net/1/9/2005/ os-1-9-2005.html, 2005.

Feistel, R.: A Gibbs function for seawater thermodynamics for $-6^{\circ} \mathrm{C}$ to $80^{\circ} \mathrm{C}$ and salinity up to $120 \mathrm{~g} \mathrm{~kg}^{-1}$, Deep-Sea Res. I, 55, 1639-1671, 2008.

Feistel, R., Wright, D.G., Jackett, D. R., Miyagawa, K., Wagner, W., Overhoff, U., Guder, C., Marion, G. M., Tchijov, V., Feistel, A. and J. H. Reissmann: Numerical implementation and oceanographic application of the thermodynamic potentials of water, vapour, ice, and seawater, Part I: Background and Equations. Ocean Sci., in preparation, 2009.

Feistel, R. and Hagen, E.: On the Gibbs thermodynamic potential of seawater, Progr. Oceanogr., 36, 249-327, 1995.

Feistel, R. and Hagen, E.: A Gibbs thermodynamic potential of sea ice, Cold Regions Sci. Technol., 28, 83-142, 1998.

Feistel, R., Nausch, G., and Wasmund, N.: State and Evolution of the Baltic Sea, 1952-2005., A Detailed 50-Year Survey of Meteorology and Climate, Physics, Chemistry, Biology, and Marine
Environment, John Wiley \& Sons, Inc., Hoboken, New Jersey, 2008.

Feistel, R. and Wagner, W.: High-pressure thermodynamic Gibbs functions of ice and sea ice, J. Mar. Res., 63, 95-139, 2005.

Feistel, R. and Wagner, W.: A new equation of state for $\mathrm{H}_{2} \mathrm{O}$ ice $\mathrm{Ih}$, J. Phys. Chem. Ref. Data, 35, 1021-1047, 2006.

Feistel, R. and Wagner, W.: Sublimation pressure and sublimation enthalpy of $\mathrm{H}_{2} \mathrm{O}$ ice Ih between 0 and $273.16 \mathrm{~K}$, Geochim. Cosmochim. Acta, 71, 36-45, 2007.

Feistel, R., Wagner, W., Tchijov, V., and Guder, C.: Numerical implementation and oceanographic application of the Gibbs potential of ice, Ocean Sci., 1, 29-38, available at: http://www. ocean-science.net/os/1/29, 2005.

Fofonoff, N. P.: Physical properties of sea-water, in: The Sea, edited by: Hill M. N., Wiley, New York, 3-30, 1962.

Fofonoff, N. P. and Millard, R. C.: Algorithms for the computation of fundamental properties of seawater, Unesco techn. pap. mar. sci., 44, 1-53, 1983.

Griffies, S. M., Gnanadesikan, A., Dixon, K. W., Dunne, J. P., Gerdes, R., Harrison, M. J., Rosati, A., Russell, J. L., Samuels, B. L., Spelman, M. J., Winton, M., and Zhang, R.: Formulation of an ocean model for global climate simulations, Ocean Sci., 1, 45-79, available at: http://www.ocean-sci.net/1/45/2005/ os-1-45-2005.pdf, 2005.

Guildner, L. A., Johnson, D. P., and Jones. F. E.: Vapor pressure of water at its triple point, J. Res. Nat. Bur. Stand., 80A, 505-521, 1976.

Haar, L., Gallagher, J. S., and Kell, G. S.: The anatomy of the thermodynamic surface of water: the formulation and comparisons with data. Proceedings of the 8th Symposium on Thermophysical Properties, edited by: Sengers, J. V., The American Society of Mechanical Engineers, New York, Vol. II, 298-302, 1982.

Haar, L., Gallagher, J. S., and Kell, G. S.: NBS/NRC Steam Tables, Hemisphere, Washington, and McGraw-Hill, New York, 320 pp., 1984.

Harvey, A. H., Peskin, A. P, and Klein, S. A.: NIST/ASME Steam Properties (NIST Standard Reference Database 10), Version 2.21, National Institute of Standards and Technology, Gaithersburg, MD, 2004.

IAPWS: Release on the IAPWS Formulation 1995 for the Thermodynamic Properties of Ordinary Water Substance for General and Scientific Use, The International Association for the Properties of Water and Steam, Fredericia, Denmark, September, available at: http://www.iapws.org/relguide/IAPWS95.pdf, 1996.

IAPWS: Guideline on the Use of Fundamental Physical Constants and Basic Constants of Water, The International Association for the Properties of Water and Steam, Gaithersburg, Maryland, USA, September 2001, revised September, available at: http://www.iapws.org/relguide/fundam.pdf, 2008.

IAPWS: Release on an Equation of State for $\mathrm{H}_{2} \mathrm{O}$ Ice Ih, The International Association for the Properties of Water and Steam, Witney, UK, September, available at: http://www.iapws.org/ relguide/Ice.pdf, 2006.

IAPWS: Release on the IAPWS Formulation 2008 for the Thermodynamic Properties of Seawater, The International Association for the Properties of Water and Steam, Berlin, Germany, September, available at http://www.iapws.org/relguide/seawater. pdf, 2008.

Jackett, D. R., McDougall, T. J., Feistel, R., Wright, D. G., and 
Griffies, S. M.: Algorithms for density, potential temperature, conservative temperature and the freezing temperature of seawater, J. Atm. Ocean. Technol., 23, 1709-1728, 2006.

Marion, G. M., Millero, F. J., and Feistel, R.: Salinity/temperature ranges for application of seawater thermodynamic models, Paper Sea-07, Proceedings of the 15th International Conference on the Properties of Water and Steam, Berlin, Germany, 7-11 September, 2008a.

Marion, G. M., Millero, F. J., and Feistel, R.: Salinity/temperature ranges for application of seawater S-T-P models, Ocean Sci., submitted, 2008b.

McDougall, T. J.: Potential enthalpy: A conservative oceanic variable for evaluating heat content and heat fluxes, J. Phys. Oceanogr., 33, 945-963, 2003.

McDougall, T. J.: On the need for the accurate representation of seawater thermodynamics in ocean climate models, Paper Sea-01, Proceedings of the 15th International Conference on the Properties of Water and Steam, Berlin, Germany, 7-11 September, 2008.

McDougall, T. J., Jackett, D. R., Wright, D. G., and Feistel, R.: Accurate and computationally efficient algorithms for potential temperature and density of seawater, J. Atm. Ocean. Technol., 20, 730-741, 2003.

McDougall, T. J., Feistel, R., Jackett, D. R., Wright, D. G., Millero, F. J., King, B. A., Marion, G. M., Spitzer, P., and Chen, C.-T. A.: Oceanographic application of the Gibbs function 2008 of seawater, Deep-Sea Res., in preparation, 2009a.

McDougall, T. J., Feistel, R., Millero, F. J., Jackett, D. R., Wright, D. G., King, B. A., Marion, G. M., Chen, C.-T. A., and Spitzer, P.: Calculation of Thermophysical Properties of Seawater, in: Global Ship-based Repeat Hydrography Manual, IOCCP Report No. 14, ICPO Publication Series no. 134, in preparation, 2009b.

Millero, F. J., Feistel, R., Wright, D. G., and McDougall, T. J.: The composition of Standard Seawater and the definition of the Reference-Composition Salinity Scale, Deep-Sea Res., 55, 5072, 2008.

Millero, F. J. and Leung, W. H.: The thermodynamics of seawater at one atmosphere, Am. J. Sci., 276, 1035-1077, 1976.

Nicholas, J. V., Dransfield, T. D., and White, D. R.: Isotopic composition of water used for triple point of water cells, Metrologia, 33, 265-267, 1996.

Preston-Thomas, H.: The international temperature scale of 1990 (ITS-90), Metrologia, 27, 3-10, 1990.
Pruß, A. and Wagner, W.: A new equation of state for water as a candidate for the New Scientific Formulation of IAPWS, in: Physical Chemistry of Aqueous Systems: Meeting the Needs of Industry, edited by: White Jr., H. J., Sengers, J. V., Neumann, D. B., and Bellows, J. C., Proceedings of the 12th International Conference on the Properties of Water and Steam. Begell House, New York, 66-77, 1995.

Riethmann, T., Wagner, W., and Feistel, R.: New equations for the melting pressure and sublimation pressure of $\mathrm{H}_{2} \mathrm{O}$ ice Ih, Paper Prop-06, Proceedings of the 15th International Conference on the Properties of Water and Steam, Berlin, Germany, 7-11 September, 2008.

Rudtsch, S. and Fischer, J.: Temperature measurements according to the International Temperature Scale of 1990 and its associated uncertainties, Accred. Qual. Assur., 13, 607-609, 2008.

Sotani, T., Arabas, J., Kubota, H., Kijima, M., and Asada, S.: Volumetric behaviour of water under high pressure at subzero temperature, High Temp. - High Press., 32, 433-440, 2000.

Tailleux, R.: On the energetics of stratified turbulent mixing, irreversible thermodynamics, Boussinesq models, and the ocean heat engine controversy, J. Fluid Mech., submitted, 2008.

Tchijov, V., Feistel, R., Cruz-León, G., and Rodríguez-Romoa, S.: Thermodynamic properties of high-pressure ices: A review, $\mathrm{Pa}-$ per Prop-07, Proceedings of the 15th International Conference on the Properties of Water and Steam, Berlin, Germany, 7-11 September, 2008a.

Tchijov, V., Cruz-León, G., Rodríguez-Romoa, S., and Feistel, R.: Thermodynamics of ice at high pressures and low temperatures, J. Phys. Chem. Solids, 69, 1704-1710, 2008b.

Tillner-Roth, R.: Fundamental Equations of State, Shaker Verlag, Aachen, 172 pp., 1998.

Wagner, W. and Pruß, A.: The IAPWS formulation 1995 for the thermodynamic properties of ordinary water substance for general and scientific use, J. Phys. Chem. Ref. Data, 31, 387-535, 2002.

White, D. R., Dransfield, T. D., Strouse, G. F., Tew, W. L., Rusby, R. L., and Gray, J.: Effects of heavy hydrogen and oxygen on the triple-point temperature of water, American Institute of Physics; CP684, Temperature: Its Measurement and Control in Science and Industry, 7, 221-226, 2003.

Wright, D. G., Feistel, R., Jackett, D. R., Miyagawa, K., Feistel, A., Guder, C., Marion, G. M., Overhoff, U., Reissmann, J. H., Tchijov, V., and W. Wagner: Numerical implementation and oceanographic application of the thermodynamic potentials of water, vapour, ice, and seawater, Part II: The Library Routines, Ocean Sci., in preparation, 2009. 